\title{
Macroscopic stress-strain response and strain localization behavior of biopolymer-treated soil
}

\section{Antonio Soldo}

Auburn University

Marta Miletic ( $\square$ mmiletic@sdsu.edu )

San Diego State University https://orcid.org/0000-0003-2120-6414

Victor Aguilar

Facultad de Ingeniería y Tecnología, Universidad San Sebastián

\section{Article}

Keywords: biopolymers, soil engineering, strain localization

Posted Date: June 22nd, 2021

DOI: https://doi.org/10.21203/rs.3.rs-540716/v1

License: (c) (1) This work is licensed under a Creative Commons Attribution 4.0 International License.

Read Full License

Version of Record: A version of this preprint was published at Polymers on February 28th, 2022. See the published version at https://doi.org/10.3390/polym14050997. 


\section{MACROSCOPIC STRESS-STRAIN RESPONSE AND STRAIN LOCALIZATION BEHAVIOR OF} BIOPOLYMER-TREATED SOIL

\author{
Antonio Soldo ${ }^{1}$, Marta Miletić2 ${ }^{2}$ Victor Aguilar ${ }^{3}$
}

\section{ABSTRACT}

Enhancement of soil engineering properties with biopolymers has been shown recently as a viable and environmentally-benign alternative to cement and chemical stabilization. Interest in biopolymer-treated soil is evident from the upsurge of related research activities in the last five years, most of which have been of experimental nature. However, biopolymers have not yet found their way into engineering practice. One of the reasons for this may be the absence of computational models that would allow engineers to incorporate biopolymer-treated soil into their designs. Therefore, the main goal of this study is to numerically capture a macroscopic stress-strain response and investigate the effect of biopolymers on the onset of strain localization. Several diagnostic strain localization analyses were conducted, thus providing strain and stress levels at the onset of strain localization, along with the orientations of the deformation band. Several unconfined compression and triaxial tests on the plain and biopolymer-treated soils were modeled. Results showed that biopolymers significantly improved the mechanical behavior of the soil and affected the onset of strain localization. The numerical results were confirmed by the digital image analysis of the unconfined compression tests. Digital image processing successfully captured high strain concentrations, which tend to occur close to the peak stress.

\footnotetext{
${ }^{1}$ Department of Civil Engineering, Auburn University, Auburn, AL, 36849-5337, USA

${ }^{2}$ Department of Civil, Construction, and Environmental Engineering, San Diego State University, San Diego, CA, 92182-1324, USA (Corresponding author)

${ }^{3}$ Facultad de Ingeniería y Tecnología, Universidad San Sebastián, Lientur 1457, Concepción 4080871, Chile
} 
23 Due to the rapid urbanization of cities and the growth of the human population, soil improvement 24 methods are of increasing importance because of the need to construct on the soft and complicated 25 ground in very adverse and hostile surroundings (Holtz et al. 1981; Hinchee and Smith 1992; Umar et al. 2016; Ashraf et al. 2017). The primary method that is conventionally applied to enhance the

27 engineering properties of the soil is chemical treatment, and one of the most commonly used 28 chemical stabilization agents is cement. Even though it is effective and cost-efficient, cement has 29 several adverse effects on the environment. For instance, it can initiate the formation of the heat islands, contaminate underground water, eradicate vegetation, prevent vegetation growth, etc.

31 However, the most severe environmental impact is the production of carbon dioxide $\left(\mathrm{CO}_{2}\right)$ during 32 the production of cement. The estimations are that the cement production industry contributes to 33 more than six percent of the world's $\mathrm{CO}_{2}$ emission in recent years (Andrew 2018). Therefore, the 34 need to replace environmentally-harmful solutions, such as cement, is in high demand.

35 One of the eco-friendly solutions is microbial induced carbonate precipitation (MICP). MICP is a biological approach that requires the presence of a large microbial community in the coarse-

37 grained soil. The reactions between microorganisms and soil particles create a cementitious bond that improves soil properties. MICP proved to be effective in increasing the strength and loadbearing capacity of the soil (DeJong et al. 2010; Chang et al. 2016; Choi et al. 2016; Umar et al. 2016; Li et al. 2018). However, this approach comes with certain drawbacks. It can result in the 41 generation of effluent ammonia, and it can only be implemented in coarse-grained soil. The reason

42 for the latter is that the pores of the fine-grained soil are very small and hence not suitable for the 43 habitation of microbes (Ashraf et al. 2017).

Another eco-friendly approach for soil stabilization is the utilization of biopolymers.

45 Biopolymers are naturally made polymers extracted from plants, shells, fungi, and yeast. They have 46 been used in the food industry, the cosmetic industry, medicine, and agriculture (Katzbauer 1998; 

known as harmless and edible, they can be considered as eco-friendly agents for soil treatment (Chang et al. 2016). Their advantage over the MICP treatment is that they can be used in both fineand coarse-grained soils, and they do not generate the effluent ammonia (Chang et al. 2015; Aguilar et al. 2016). Up to date, several research studies have shown the positive biopolymer effect on the

52 soil strength improvement, permeability reduction, and soil collapsibility decrease (Chang et al.

53 2015; Ayeldeen et al. 2017; Wiszniewski et al. 2017; Cabalar et al. 2017; Soldo and Miletić 2019;

54 Toufigh and Kianfar 2019; Soldo et al. 2020).

The vast majority of the research on biopolymer-treated soil was experimental in nature.

56 One of the reasons why biopolymer treatment of soil has not found its way into civil engineering

57 practice could be the absence of computational models that would allow engineers to incorporate

58 biopolymer-treated soil into their designs. Some of the research that conducted numerical modeling

59 is by Ayeldeen et al. (2017). They created a finite element model to investigate the behavior of the

60 treated collapsible soil after and before water immersing. The treated and untreated soils were

61 simulated by Mohr-Coulumb's criterion with an associated flow rule. The commercially available

62 finite element software Plaxis 2D was used. The results of the numerical analysis showed the

63 treating soil with a biopolymer would increase the soil bearing capacity and reduce soil settlement

64 during and after saturation. The results of the numerical analysis on untreated soils were in close

65 agreement with the results of the in situ plate load tests.

Another example of numerical modeling of the biopolymer treated soil was presented by

67 Chen et al. (2016). In their experimental and numerical research, surface strength of biopolymer-

68 treated mine tailings, made of finely ground rock, was investigated. They conducted experimental

69 research on the biopolymer effect on the penetration force of a cylindrical penetrometer. In the

70 numerical part of their study, they used the discrete element method to simulate the penetration

71 test on the mine tailings stabilized with biopolymer solutions. Their numerical analysis, which was 
72 conducted in PFC3D v4.0 using the parallel bond model, showed coinciding results with their

73 experimental analysis. The numerical simulations showed an increase in the tensile and shear

74 strengths with higher biopolymer concentration, indicating that the higher concentration of

75 biopolymer causes larger inter-particle bonding.

76 To the best knowledge of authors, no previous attempts have been made towards

77 conducting a diagnostic strain localization analysis in biopolymer-treated soil. Strain localization is

78 a characteristic of elastic-plastic materials that indicates the onset of narrow deformation bands. It

79 is characterized by a jump in strain rate and is followed by reduction of a load-carrying capacity,

80 which often indicates an imminent failure of the materials and structures. Thus, the main goal of

81 this study was to numerically capture and experimentally validate a macroscopic stress-strain

82 response and predict the onset of strain localization in elastic-plastic biopolymer-treated soil. In

83 particular, this study focused on soil treated with three types of biopolymers that were modeled by

84 the linear Drucker-Prager model. A combined numerical-analytical algorithm that can capture a

85 stress-strain response and inception of strain localization in biopolymer-treated soil was

86 implemented. Actual unconfined compression and unconsolidated undrained tests, which were

87 performed on plain and biopolymer-treated soil, were modeled. The analyses presented herein

88 allowed an improved characterization of the biopolymer effect on the failure initiation by providing

89 stress and strain levels at the onset of strain localization, as well as orientations of the

90 accompanying discontinuities and corresponding strain localization modes. Ultimately, a diagnostic

91 strain localization analyses provided a quantitative measure of biopolymer contribution toward

92 increased resilience and toughness of these important and evironemtally friendly materials.

93 Following the introduction in this section, a detailed description of the experimental

94 program is provided. This is followed by the description of conditions for the onset of

95 discontinuous bifurcations and an application to the Drucker-Prager model. Finally, calibration of 
constitutive models, stress-strain responses, and predictions for the onset of strain localization are

97 presented. A summary of major findings is provided at the end.

\section{EXPERIMENTAL RESEARCH}

$99 \underline{\text { Soil }}$

100 Two types of sand were used as a base material in this study, silty sand and pure sand. Both sand

101 types were classified following the ASTM D6913-17 and ASTM D4318-17 standards. The silty sand

102 had 39\% fine particles with the liquid limit, plastic limit, and the index of plasticity being 49, 29,

103 and 20, respectively. Therefore, according to the Unified Soil Classification System, fine particles

104 were classified as silt with low plasticity, and the overall classification of this soil was SM (silty 105 sand).

106 The pure sand was obtained from a site close to Destin, Okaloosa County, Florida, USA. It 107 was mostly made of quartz and was highly uniform. Fine particle content was almost non-existent.

108 The coefficient of uniformity and the coefficient of curvature that were calculated from the grain 109 distribution curve were 1.46 and 0.93 , respectively. Since the presence of gravel and fine particles 110 was practically non-existent, USCS classifies this sand as SP (poorly graded sand). This type of sand 111 was investigated only for the image processing segment of this research.

\section{Biopolymers}

\section{Xanthan gum}

114 Xanthan gum (XG) is a biopolymer created by the fermentation of a carbohydrate-source medium 115 such as glucose. Xanthan gum was named after the bacterium that induces the process of 116 fermentation, Xanthomonas campestris. Xanthan gum is easily dissolved in hot and cold water. 117 Solutions containing Xanthan gum are non-Newtownians with high pseudoplasticity. At the low 118 shearing rate, the xanthan gum chains are in the state of rest and bound by hydrogen bonds. 119 Increasing the shear rate, the bonds are reduced, which leads to lower viscosity. Due to its fast 
120 interaction with water, rapid agitation and mixing are needed to dissolve xanthan gum in water

121 efficiently. The chains of xanthan gum remain stable over wide ranges of pH values. Therefore, it

122 can be successfully implemented in cleaning products as well as acidic food additives (Katzbauer

123 1998). Other than that, it can be found in the cosmetic industry, agriculture, and oil drilling industry

124 (Katzbauer 1998).

125 Guar gum

126 Guar gum (GG) is a biopolymer extracted from Cyamopsis tetragonoloba that is commonly known as

127 guar. Unlike the majority of plant-based gums, guar gum does not have any uronic acid in its

128 molecular structure. Also, it has a high molecular weight when compared with other naturally 129 occurring water-soluble polysaccharides. It is worth mentioning that guar gum formations are 130 stable over a broad range of $\mathrm{pH}$. Therefore, it can be dissolved in water. Even small concentrations 131 of guar can significantly increase the viscosity of the solution it is mixed in. Some of its applications 132 can be found in the cosmetic industry, food industry, agriculture, and oil drilling (Thombare et al. 133 2016).

\section{Beta-glucan}

135 Beta-glucan (BG) is a biopolymer that consists of glucose molecules. It is extracted from the cells of 136 yeast, fungi, some types of bacteria, and certain types of cereals. The molecular structure of beta137 glucans depends on the source they were extracted from. Beta-glucans molecules can vary on the 138 kind of linkages, branching, molecular weight, solubility, and polymer charge (Volman et al. 2008).

139 Beta-glucan used in this study was Beta 1.3/1.6 glucan. The extraction process of beta-glucan 140 depends on the parent source and the molecular bonds of the polymer. Therefore, an appropriate 141 solving agent has to be selected. Molecular structures of beta-glucan that are held loosely outside 142 the cells can be extracted with hot water. Beta-glucan molecules that are held tightly to the cell 143 walls can be released by hot alkali. Beta-glucan, in its powder form, can be dissolved in hot and cold 
144 water, which results in forming a gelatinous solution (Bacic et al. 2009). Beta-glucans are heavily 145 investigated in medicine for health improvement (Volman et al. 2008; Bacic et al. 2009).

\section{Specimen preparation}

147 All specimens were prepared by dry mixing of biopolymer and silty sand. The biopolymer

148 concentrations that were used were $0,1,2,4 \%$ with respect to the mass of the soil, where $0 \%$ 149 represents the plain soil with no additives. After the biopolymer was uniformly mixed with soil, 150 water was sprayed up to $16.5 \%$ of the soil mass. After the water was homogeneously added to the 151 biopolymer-soil mixture, the biopolymer-soil was compacted in the molds that were intended for 152 the unconfined compression, splitting tensile, and triaxial tests.

153 The mold for the specimens which were tested for unconfined compression had a diameter 154 of $3.3 \mathrm{~cm}$ and a height of $7.1 \mathrm{~cm}$. Additionally, several cube specimens with dimensions of $5 \times 5 \times 5 \mathrm{~cm}$ 155 were made to monitor the development of the strain and detect the inception of strain localization 156 during the unconfined compression test by means of digitial image correlation. The cube specimens 157 were chosen because of the flat surface of the sides of the cube. Specimens for the triaxial test had a 158 mold with a diameter of $7 \mathrm{~cm}$ and a height of $14 \mathrm{~cm}$. Furthermore, specimens for the splitting 159 tensile strength test were made with attention to use them for calibration of the numerical model. 160 The mold that was used to make the specimens for the splitting tensile strength test had a diameter 161 and height of 3.5 and $1.8 \mathrm{~cm}$, respectively. After preparation, specimens were extruded from the 162 molds and left to cure for five days (specimens for the unconfined compression and splitting tensile 163 test) of time and seven days (specimens for the triaxial test). The reason for different curing time is 164 the fact that the triaxial specimens were larger and required more curing time to achieve their full 165 strength. 
167 For determination of strength in the unconfined compression test, the axial load was applied with a

168 strain rate of $1.5 \% / \mathrm{min}$, as per ASTM D2166. The compressive strength of the specimen was

169 computed by dividing the maximum load attained during the test by the corresponding cross-

170 sectional area of the specimen.

171 The unconsolidated undrained test was performed in accordance with ASTM D2850-15. The

172 specimens were placed in a plexiglass chamber under the confining pressure of $100 \mathrm{kPa}$. During the

173 shearing stage of the test, the axial strain was applied under the rate of $0.7 \% / \mathrm{min}$.

174 Splitting tensile tests were performed following general procedures described in the ASTM

175 D3967-16 but with a modified apparatus to accommodate small specimen sizes and relatively low

176 loads. The load was applied at the constant strain rate of $1.5 \% / \mathrm{min}$. It must be noted that the

177 splitting tensile test does not give direct soil tensile properties. Thus, the tensile strength was back-

178 calculated from the maximum compressive load and the dimension of the specimens using the

179 following formula (Akin and Likos 2017):

$180 \quad \sigma_{T}=\frac{2 P}{\pi L D}$

181 where $\sigma_{T}$ is tensile strength; $P$ is a compressive force at failure; $D$ is the diameter of the specimen; $L$

182 is specimen thickness.

\section{Digital image acquisition and processing}

184 The digital image processing technique was used to monitor the development of the strain

185 component and detect the inception of strain localization. The cube specimens were chosen

186 because of the flat surface of the sides of the cube. The flat surface of the cube specimens was

187 appropriate for the image processing software (GOM Correlate) that can record the strain 188 development in pressure-sensitive materials. 
190 pattern, a distinctive speckle pattern was applied to the surface of the specimen with a colored

191 marker. The digital images of the soil samples were continuously recorded at a constant position

192 (20 $\mathrm{cm}$ from the center of the specimen) for image consistency and uniformity. The resolution of

193 the camera was $12 \mathrm{MP}$, and it was able to capture 30 frames per second.

194 The image processing software splits the recording as a series of images. The applied 195 pattern is recognized by the software and isolated as a surface of observation. That surface is 196 transformed into a group of pixels. In this study, the surface of interest $(45 \times 45 \mathrm{~mm})$ was 197 transformed into approximately $570 \times 570$ pixels. The position of each pixel and the distance from 198 the surrounding pixels are tracked through the software. Each picture is compared to the previous 199 one, therefore the software can detect the change of the pixel position. Following that technique, 200 the software can detect and quantify displacement and strains that occur in the initial recording. 201 Furthermore, the unconfined compression apparatus stores timestamps through the test, while the 202 image processing software takes the time steps from the video recording. Therefore, the correlation 203 between the experimental results and the image processing software could be drawn.

205 NUMERICAL MODELING

\section{Stress-strain relationship}

207 The biopolymer-treated soil was assumed to be an elastic-plastic material experiencing an 208 infinitesimal strain and obeying a general non-associative flow rule. Normal components of stress 209 and strain tensors are positive in tension herein. The macroscopic stress-strain relationship for 210 plastic loading is given by (Miletić 2016, Miletić and Perić 2018):

$211 \quad \dot{\sigma}_{i j}=D_{i j k l}^{e}\left(\dot{\varepsilon}_{k l}-\dot{\varepsilon}_{k l}^{p}\right)$ 
212 where subscript notation represents the order of the tensor, superscripts indicate elastic (e), plastic

213 (p) or elastic-plastic (ep) component, “.” over a symbol represents "rate” (time derivative).

214 Therefore, $\dot{\sigma}_{i j}, \dot{\varepsilon}_{i j}$, and $\dot{\varepsilon}_{i j}^{p}$ are the rates of a second-order Cauchy stress tensor, infinitesimal strain

215 tensor, and infinitesimal plastic strain tensor, respectively. $D_{i j k l}^{e}$ is the corresponding elastic

216 stiffness moduli tensor of the biopolymer-treated soil, and is given by (Miletić and Perić 2018):

$217 \quad D_{i j k l}^{e}=\mu\left(\delta_{i k} \delta_{j l}+\delta_{j k} \delta_{i l}\right)+\lambda \delta_{i j} \delta_{k l}$

218 and $\delta_{i j}$ is Kronecker delta, and $\mu, \lambda$ are Lamé's constants of the composite.

219 The two-invariant yield function $(F)$ was used to describe the plastic behavior of a pressure220 sensitive cementitious biopolymer-treated soil. It is defined as:

$221 \quad F=F\left(\sigma_{i j}, \kappa\right)$

222 where $\kappa$ is a plastic hardening variable.

223 The plastic flow rule and hardening law are respectively given by:

$224 \quad \dot{\varepsilon}_{i j}^{p}=\dot{\lambda} \frac{\partial G}{\partial \sigma_{i j}}$

225 and

$226 \quad \dot{\kappa}=h\left(\dot{\varepsilon}_{i j}^{p}\right)=\dot{\lambda} h\left(\frac{\partial G}{\partial \sigma_{i j}}\right)$

227 where $\dot{\lambda} \geq 0$ is a plastic multiplier, $h\left(\dot{\varepsilon}_{i j}^{p}\right)$ is the first order homogeneous generally nonlinear

228 function, and $G$ is a plastic potential function. The non-associated flow rule was used to more 229 realistically model the behavior of treated pressure-sensitive materials such as biopolymer-soils 230 (Hirai et al. 1989; Rahimi et al. 2015).

231 The plastic multiplier $\dot{\lambda}$ is obtained from the consistency condition in plastic loading, as:

$232 \quad \dot{\lambda}=\frac{f_{i j} D_{i j k l}^{e} \dot{\varepsilon}_{k l}}{H+f_{i j} D_{i j k l}^{e} g_{k l}}$ 
233 where gradients of a yield function and plastic potential are denoted by $f_{i j}$ and $g_{i j}$, respectively. The 234 actual hardening modulus $H$ is given by:

$235 \quad H=-\frac{\partial F}{\partial \kappa} h\left(g_{i j}\right)$

236 It is positive, negative, or zero for hardening, softening, or perfect plasticity, respectively.

237 By combining Eqs. (2), (5), and (7), a tangent elastic-plastic stiffness moduli tensor $D_{i j k l}^{e p}$ is 238 obtained as:

$239 D_{i j k l}^{e p}=D_{i j k l}^{e}-\frac{D_{i j m n}^{e} g_{m n} f_{p r} D_{p r k l}^{e}}{H+f_{m n} D_{m n p r}^{e} g_{p r}}$.

240 The yield function, $F$, and rate of the plastic multiplier satisfy Kuhn-Tucker conditions as 241 follows:

$242 \quad \dot{\lambda} \geq 0, F(\sigma, \kappa) \leq 0, \dot{\lambda} F(\sigma, \kappa)=0$.

\section{Onset of strain localization}

244 The diagnostic strain localization analysis was performed on the constitutive level. The inception of

245 strain localization may be considered as a bifurcation problem that signifies a loss of stability of the 246 constitutive relation governing a uniform deformation.

247 It is assumed that the jump in a displacement rate along the singular surface $\Gamma$ is constant, 248 which is expressed as (Miletić and Perić 2018):

$\left.249\left[\dot{u}_{i}\right]\right|_{\Gamma}=\left.\left(\dot{u}_{i}^{+}-\dot{u}_{i}^{-}\right)\right|_{\Gamma}=$ constant

250 where $\dot{u}_{i}^{+}$denotes the displacement rate on one side of the $\Gamma$ and $\dot{u}_{i}^{-}$the other side.

251 Equation (11) generally describes the kinematics of a strong discontinuity. The special case

252 obtained by equalizing the right-hand side of Equation (5.10) to zero represents a weak 253 discontinuity. At this point, no assumptions are made about the homogeneity and variation of $\left[\dot{u}_{i}\right]$ 
254 in the neighborhood of the singular surface $\Gamma$. Combining Eq. (11) with the kinematical definition of 255 infinitesimal strain rate gives the following expression for a jump in strain rate across the singular 256 surface $\Gamma$ :

$\left.257 \quad\left[\dot{\varepsilon}_{i j}\right]\right|_{\Gamma}=\frac{1}{2}\left(z_{i} n_{j}+z_{j} n_{i}\right)$

258 where $z_{i}$ is the eigenvector corresponding to the relevant eigenvalue problem, as discussed below, $259 n_{i}$ is the unit vector that is normal to the surface $\Gamma$.

260 Furthermore, the equilibrium along the singular surface imposes the following condition on 261 the traction rate $(\dot{t})$ :

$\left.262\left[\dot{t}_{i}\right]\right|_{\Gamma}=\left.\left(\dot{t}_{i}^{+}-\dot{t}_{i}^{-}\right)\right|_{\Gamma}=0$

263 Combining Equations (2), (12), and (13) leads to the classical bifurcation criterion (Rudnicki and 264 Rice 1975) which is, given by:

$265 \quad Q_{i k} z_{k}=n_{i} D_{i j k l}^{e p} n_{l} z_{k}=0$

266 where $Q_{i k}$ is an acoustic tensor, also known as a characteristic tangent stiffness tensor. Equation

267 (14) is based on the assumption that a so-called plastic/plastic bifurcation precedes an 268 elastic/plastic bifurcation. In the former case, the primary and bifurcated incremental fields both 269 correspond to plastic loading, while in the latter, only one of the incremental fields corresponds to 270 plastic loading. It was shown (Ottosen and Runesson 1991) that the plastic/plastic bifurcation 271 always precedes elastic/plastic bifurcation.

272 In order to solve for the critical amount of hardening necessary for the onset of strain 273 localization, the following eigenvalue problem was considered:

$274 \quad Q_{i k} z_{k}^{(j)}=\lambda^{(j)} Q_{i k}^{e} z_{k}^{(j)}, j=1,2,3$

275 where $(j)$ indicates the direction of principal stresses. 
$277 Q_{i k}$ is singular. The first two eigenvalues are elastic and equal to one while the third eigenvalue is 278 plastic, and it was given by Runesson et al. (1991) as:

$279 \quad \lambda^{(3)}=1-\frac{b_{i} P_{i k}^{e} a_{k}}{H+f_{m n} D_{m n p r}^{e} g_{p r}}$

280 where $P_{i k}^{e}$ is the inverse of the elastic acoustic tensor and the vectors $a_{i}$ and $b_{j}$ are defined as

$281 \quad a_{i}=f_{m n} D_{m n i j}^{e} n_{j}, b_{j}=n_{i} D_{i j m n}^{e} g_{m n}$

$282 \quad(17)$

283 The corresponding eigenvector is given by the following expression:

$284 \quad z_{i}^{(3)}=k P_{i j}^{e} b_{j}$

285 where $k$ is an arbitrary scalar.

286 By setting $\lambda^{(3)}$ from Equation (16) equal to zero, a hardening modulus $H\left(n_{i}\right)$ was obtained. 287 Finally, the critical amount of hardening necessary for the onset of strain localization was obtained 288 by solving the following constrained optimization problem:

$289 \quad H_{c r}=\max _{n_{i}} H\left(n_{i}\right) \quad$ where $n_{i} n_{i}=1$

290 where the right side of the equation above represents the maximization of the function. The 291 corresponding bifurcation angle $\theta$ represents the angle between the minor stress axis and the 292 normal vector $\left(\mathrm{n}_{1}, 0, \mathrm{n}_{3}\right)$. It can be determined from the expression:

$293 \tan ^{2} \theta=\frac{n_{1}^{2}}{n_{3}^{2}}$

294 Analytical solutions for $H_{c r}$ and corresponding critical bifurcation angles were given by (Ottosen 295 and Runesson 1991). 
297 The analysis, in this study, was based on the linear Drucker-Prager model and the parameters of the

298 total stress. Yield and plastic potential function were presented as follows:

$299 \quad F=\left(\frac{1}{3} \tan \beta\right) I_{1}+\sqrt{J_{2}}-\kappa$

$300 \quad G=\left(\frac{1}{3} \tan \psi\right) I_{1}+\sqrt{J_{2}}$

301 Gradients of linear Drucker-Prager yield and plastic potential functions are given by

$302 \quad f_{i j}=\frac{1}{3} \tan \beta \cdot \delta_{i j}+\frac{\sqrt{3}}{2 \sqrt{J_{2}}} S_{i j}$

$303 \quad g_{i j}=\frac{1}{3} \tan \psi \cdot \delta_{i j}+\frac{\sqrt{3}}{2 \sqrt{J_{2}}} S_{i j}$

304 where $s_{i j}$ is stress deviator tensor; $\beta$ is internal friction angle; $\psi$ is dilatancy angle; $I_{1}$ and $J_{2}$ are first

305 and second deviatoric stress invariants, respectively.

306 After the critical hardening has been obtained, the onset of strain localization can be

307 determined. The onset can be determined by comparing the values of the critical hardening

308 modulus with the actual hardening modulus. The actual hardening modulus $\left(\mathrm{H}_{\text {act }}\right)$ is calculated from

309 the response representing the actual stress and plastic strain.

\section{$310 \quad$ Numerical simulation}

311 The actual stress-strain response was obtained by simulating the samples by a single eight-node

312 element modeled with 3D integration. The unconfined compression tests were conducted by

313 applying a constant vertical strain rate and keeping the principal stresses in the horizontal

314 directions at zero. The unconsolidated undrained tests were performed under a constant vertical

315 strain rate and applying the horizontal pressures following the experimental tests. The inception of 
316 the strain localization will occur at the moment when the actual hardening modulus equalizes with 317 the critical hardening modulus.

\section{Calibration of constitutive model}

319 The Drucker-Prager model was calibrated against the unconfined compression, splitting tensile 320 strenght test, and the unconsolidated undrained tests that were performed on plain and 321 biopolymer-treated silty sand. The calibration example is presented in Fig. 1.

322 The experimental data were available for the plain soil and the soil treated with three 323 biopolymer concentrations (1, 2, and 4\%). However, only the data for the soil treated with 0,1 , and $3244 \%$ was used for the calibration. The data for the soil treated with $2 \%$ biopolymers was used for the 325 validation of the proposed model. The elastic and plastic parameters were predicted from linear 326 interpolation of the results for the soil with 0,1 , and $4 \%$ biopolymers. To achieve the best values of

327 the input parameters, the least-squares fit was used. The least-squares fit minimizes the relative 328 error, and it was based on the experimental data.

Young's modulus was obtained for the plain and treated soil from the unconfined 330 compression tests. The Young's modulus was calculated as the slope of the elastic portion of the 331 stress-strain response. The calculated values of Young's modulus for the plain and treated soil were 332 in the range of previously reported values (Truty and Obrzud 2011; Chang et al. 2015). Poisson's 333 ratio $(v)$ was kept constant for all biopolymer-treated soil and was selected from the recommended 334 values for different types of materials (Das 2019).

$335 \quad$ For the linear Drucker-Prager criterion used in this study, the internal friction angle $(\beta)$ and 336 cohesion (d) were taken from the linear yield surface in the p-q stress plane (Figure 5-1). The 337 cohesion for the samples with $2 \%$ of biopolymers was calculated from the predicted friction angle 338 and the initial stress level of the predicted hardening. The plasticity models for the nonassociated 339 flow require a value for the dilatation angle $(\psi)$ that was kept constant for all biopolymer-treated 
340 soil and was assumed based on suggested values (Strömblad 2014). Table 1 summarizes the 341 material properties used for the proposed model.

342 The isotropic non-linear hardening was used in all test simulations and was implemented 343 into the model in a tabular form. The hardening was obtained from the averaged values of the 344 experimental tests (unconfined compression). The plastic strains were calculated by subtracting 345 the elastic strain components from the amount of total strains. Prior to that, the elastic strain 346 components were calculated by dividing the axial stress response with the modulus of elasticity.

347 The example of actual and predicted hardening response for the unconfined compression is 348 presented in Fig. 2. The hardening curve for the silty sand with $2 \%$ BG was interpolated from the 349 parameters of the equations fitting the experimental data.

\section{$350 \quad$ RESULTS}

$351 \quad$ Unconfined compression test

352 The linear Drucker-Prager model was used to simulate the 3D stress state of the unconfined 353 compression tests. A comparison between the numerically predicted responses and experimentally 354 observed response for the unconfined compression test are presented in Fig. 3 - Fig. 5. The stress355 strain responses of specimens with 0,1 , and $4 \%$ were used for calibration of the model, while the 356 specimens with $2 \%$ were used for validation.

357 Fig. 3 shows the numerical response (solid line) and experimental data (scatter data) of the 358 unconfined compression test of the BG-treated silty sand. For comparison, the same results of the 359 plain silty sand are shown Fig. 3a). From Fig. 3 it can be seen that the onset of strain localization 360 (OSL) of the silty sand increased with the addition of BG. Furthermore, it can be seen that the peak 361 stress also increased with the biopolymer addition. Fig. 3a, b, and d show a relatively better match 362 between the experimental data and the numerical response when compared with Fig. 3c. That is 363 because of the numerical response in Fig. 3a, b, and $d$ was based on the calibrated material 
properties, whereas the numerical response in Fig. 3c was obtained from the predicted material properties. The predicted model could not detect the OSL for the silty sand treated with $4 \%$ BG because the actual critical hardening never equalized with the calculated critical hardening. In compression test of the XG-treated silty sand. The same results of the silty sand are shown in Fig. raise to the level of the calculated critical hardening.

Fig. 4, the numerical response and experimental data of the unconfined compression test of the GG-treated silty sand can be seen. Additionally, the experimental and numerical results of the treated silty sand were compared with the results of the plain silty sand (

Fig. 4a). It can be seen that the peak stress increased with the increase of the GG concentration.

Fig. 4 shows that the OSL of the silty sand increased with the addition of GG. The exception is the concentration of $1 \%$ GG (

Fig. 4b). Even though the peak stress of the silty sand increased with the addition of $1 \% \mathrm{GG}$, the OSL occurred at the lower strain level for 1\% GG. The reason behind that is that the onset of strain localization depended on the yield stress and the peak stress, but it was primarily governed by the hardening response. Furthermore, the numerical response of the silty sand with $2 \%$ GG shows a relatively good match with the experimental data (

Fig. 4c).

Fig. 5 shows the experimental data and the numerical response of the unconfined can be seen that the peak stress also increases with the increase of XG. The numerical response of the silty sand treated with $2 \%$ XG showed a relatively good correspondence with the experimental data even though it was based on the predicted material properties. The predicted model could not detect the OSL for the silty sand treated with $4 \%$ XG because the actual critical hardening did not

390 (Fig. 6b). It is evident that the stress at OSL increased with the increase of biopolymer 391 concentration, and that the level of total strain increased for most of the biopolymer 392 concentrations. 
394 unit vector (n) that lays in the $\mathrm{x}_{1}, \mathrm{x}_{3}$ plane (Ottosen and Runesson 1991). From Fig. 7, it can be seen 395 that the addition of the biopolymers altered the bifurcation angle. In particular, the results show 396 that the bifurcation angle kept increasing with the increase of the GG and BG concentrations. For 397 the XG-treated soil, the highest bifurcation angle was achieved for the concentration of $1 \%$, and it 398 kept decreasing with the increase of XG concentration. That phenomenon can be related to the 399 increase in the ductility of the material with the increase of the XG concentration. However, in all 400 cases of the treated soil, the bifurcation angle was higher than the bifurcation angle of the plain soil. 401 In general, the increase of the bifurcation angle results in a steeper deformation bend that changes 402 the failure behavior.

\section{$403 \quad$ Unconsolidated-undrained triaxial test}

404 The linear Drucker-Prager model was also used to simulate the 3D stress state of the 405 unconsolidated-undrained triaxial test. The experimental stress-strain response was compared 406 with the numerical response. The onset of strain localization was considered when the actual 407 hardening equalized with the critical hardening. The results were summarized in Fig. 8. The level of 408 the stress at OSL increased with the increase of the biopolymer concentration (Fig. 8a). However, 409 Fig. 8 shows a trend of the decreasing level of strain at OSL with the increase of biopolymer 410 concentration. The reason for that behavior is the fact that the onset of strain localization depends 411 on the yield stress and the hardening response. These results indicate that the biopolymer-treated 412 soil had a more brittle behavior than the plain soil at the higher confining pressures.

413 The change in the bifurcation angle of triaxial specimens (Fig. 8c) showed a similar 414 response, as seen in the unconfined compression test. For all biopolymer types and biopolymer 415 concentrations, the treated soil had a higher bifurcation angle than the plain soil. Additionally, the 416 bifurcation angle kept increasing with the concentration increase of GG and BG. For the XG-treated 
417 soil, the highest bifurcation angle was achieved for the concentration of $1 \%$, and it kept decreasing 418 for the higher concentrations of XG.

419 Fig. 9 compares the stress-strain responses of the unconfined compression tests and the 420 triaxial tests of the silty sand. As described previously, the onset of strain localization occurs close 421 to the peak of stress-strain curves. Comparing the peaks of the unconfined compression and triaxial 422 test curves, it can be observed that the peaks occur at a higher stress-strain level for the triaxial 423 tests. The reason for that is the applied confinement pressure in the triaxial test. Schnaid et al. 424 (2001) demonstrated that the increase in confinement pressure increases the level of the peak 425 stress in the cemented sand and it postpones the level of strain at which it occurs. Furthermore, the 426 peak stress tends to increase with the increase of biopolymer concentration. Observing only the 427 results of the unconfined compression tests, represented with scattered data, it can be seen that 428 biopolymers tend to increase the level of the peak stress and the level of strain at the peak 429 (represented by the arrow in Fig. 9). The triaxial test results, represented by solid lines, also show 430 that the level of the peak stress increases with the addition of biopolymers. However, the peak 431 occurs at the lower strain level for the treated silty sand than for the plain silty sand. Furthermore, 432 the level of strain tends to decrease with the increase of biopolymer concentration (represented by 433 the arrow in Fig. 9). Similar results were demonstrated in previous research of the stabilized soil 434 (Schnaid et al. 2001; Kutanaei and Choobbasti 2016). That phenomenon is likely related to the 435 ductility of the specimens. The plain soil in the triaxial test demonstrates a more ductile behavior 436 than the treated specimens. Cemented soil can have an abrupt post-peak failure in the triaxial test 437 (Tagliaferri et al. 2011) that indicates the brittleness of the treated soil. It is also more prominent in 438 the sand with no or a small amount of fine particles. 
440 Fig. 10 and Fig. 11 combine experimental response, numerical response, and image processing 441 results for clean sand, and silty sand, respectively. The experimental responses of the unconfined 442 compression tests were presented by markers in Fig. 10and Fig. 11. The solid dark and red lines 443 represent the numerically obtained stress-strain curve, and OSL, respectively.

444 The heat maps in Fig. 10 and Fig. 11 are presented as overlays on the soil surface and show 445 the strain concentration and strain propagation on cube samples. Three heat maps represent three 446 different timestamps when the heat map was generated. The first image represents the early stage 447 of the unconfined compression with no visible strain localization. The second image corresponds to 448 the OSL from the analytical-numerical algorithm. The third image represents the post-peak strain 449 propagation. The arrows in the figures represent the stress-strain level at which the heat map was 450 captured.

451 Fig. 10a represents the sand treated with $0.5 \% \mathrm{XG}$, whereas Fig. 10b represents the sand 452 treated with $1 \%$ XG. Comparing the onset of strain localization in the sands with different XG 453 concentrations, it can be seen that OSL occurs for almost the same strain level, in fact, moderately 454 lower for the sand with $1 \%$ XG. However, the peak stress reached was higher for the specimen 455 treated with $1 \%$ XG. Shortly after reaching the peak stress, the stress drops more abruptly for the 456 specimen with $1 \%$ XG because of the increased brittleness.

457 The heat maps in Fig. 10a and Fig. 10b show the process of strain concentration for the sand 458 specimen. In both figures, in the early stages of the test, the strain distribution is uniform along the 459 whole surface. While approaching the red line (OSL), the strains start to concentrate in one 460 deformation plane. The third heat map image shows the propagation of the deformation plane with 461 the increase in strain after the OSL has been reached. Additionally, the heat map shows the created 462 bifurcation angle as the result of the strain localization. The bifurcation angle of sand with $0.5 \%$ XG 463 was calculated as $65^{\circ}$, while the bifurcation angle of sand with $1 \%$ XG was $75^{\circ}$. It can be concluded 
464 that the increase of biopolymer concentration can increase the bifurcation angle of sand. A similar 465 trend was previously reported for the biopolymer-treated silty sand where the bifurcation angle 466 was found through the analytical-numerical algorithm.

467 Observing Fig. 11, a combined experimental response, numerical response and image 468 processing results for silty sand can be seen. Fig. 11a represents the plain silty sand, Fig. 11b 469 represents the silty sand treated with $0.5 \%$ XG, and Fig. 11c shows the silty sand with 1\% GG. Even 470 though the peak stress increased with the addition of biopolymers, the strain level for the OSL did 471 not significantly change. This indicates that higher concentrations of XG and GG are required to 472 postpone the OSL of the silty sand.

473 The heat maps in Fig. 11a, Fig. 11b, and Fig. 11c show the process of strain concentration for 474 the biopolymer-treated silty sand. In all three figures, in the early stages of the test, the strain 475 distribution is uniform along the specimens' surfaces. While approaching the OSL, the strains start 476 to concentrate on one deformation plane. The second image shows the high strain concentration at 477 the moment of the OSL which was determined from the analytical-numerical algorithm. The third 478 heat map image shows the strain propagation that occurs after the OSL. Additionally, the heat maps 479 show the created bifurcation angle due to the strain concentration. The bifurcation angle of the 480 biopolymer treated soil shows higher values for the biopolymer-treated silty sand. The plain silty 481 sand (Fig. 11a) had the bifurcation angle of $55^{\circ}$. The silty sand with $0.5 \%$ XG Fig. $11 \mathrm{~b}$ ) had the 482 bifurcation angle of $60^{\circ}$, while the concentration of $1 \%$ GG (Fig. 11b) resulted in the bifurcation 483 angle of $70^{\circ}$. As reported previously in this study, the bifurcation angle of the silty sand increased 484 with the addition of biopolymers. The difference between the second heat map image (at the OSL), 485 and the third image (after the OSL) was more prominent in the sand than in the silty sand. The 486 reason for that is the difference in the nature of the base material. The treated sand had a more 487 brittle response than the treated sand wilt. Furthermore, the break of the treated sand was cleaner, 
whereas the failure of the silty sand resulted in the partial crumbling of the material. Therefore, the nature of the treated sand was more suitable to observe under the image processing software.

491 high strain concentrations at the moment of the OSL. However, there are some drawbacks that 492 should be considered. The image acquisition with a single camera and subsequent processing gave 493 a 2D output only on one side of the specimen. However, during the actual 3D test, it is unknown on 494 which specimen side will the deformation band occur. Therefore, the digitally obtained deformation 495 planes for the tested specimens might not be the most critical ones. To solve these issues, multiple 496 cameras facing each specimen side should be used.

\section{CONCLUSIONS}

499 The main objective of this research was to perform the computational and experimental diagnostic 500 strain localization analyses in biopolymer-treated soil. Two types of soil (silty sand and clean sand) 501 were investigated together with the three types of biopolymers (xanthan gum, guar gum, and beta502 glucan). A numerical-analytical algorithm was implemented to capture the stress-strain response 503 and the inception of the strain localization. The experimental data were collected for the plain silty 504 sand and silty sand with 1,2, and 4\% biopolymer concentrations. Three tests used for the 505 calibration purposes were unconfined compression, unconsolidated undrained triaxial, and 506 splitting tensile strength tests. However, the experimental data of the silty sand with $2 \%$ 507 biopolymers was not used for the calibration, but only for validation purposes.

508 The stress-strain response of the specimens subjected to uniaxial compression and triaxial 509 stress states were simulated. In addition, the inception of the strain localization was calculated for 510 each specimen and each stress state. For the unconfined compression test, it was found that the OSL 511 was postponed for most concentrations of biopolymers. The peak stress in each test increased with 512 the increase of biopolymer concentration, and OSL always occurred close to the level of the peak 
513 stress. The level of the bifurcation angle of the silty sand increased for all biopolymer 514 concentrations. It was noticed that the increase of GG and BG concentration increases the 515 bifurcation angle. However, for XG, the highest bifurcation angle was noticed for $1 \%$ XG, and it kept 516 decreasing for higher concentrations.

$517 \quad$ The unconsolidated undrained triaxial test showed an increase in the peak stress of the silty 518 sand for all biopolymer concentrations. Also, the increase in the bifurcation angle was noticed for 519 all biopolymer concentrations. The same trend as in the unconfined compression test was noticed. 520 The increase of GG and BG concentrations lead to an increase in the of the bifurcation angle. The 521 highest achieved bifurcation angle for XG treated silty sand was achieved at 1\% XG. For higher 522 concentrations, the bifurcation angle started decreasing. However, it was noticed that for the 523 triaxial state of stress, OSL occurred close to the peak stress, and it was advanced for every tested 524 biopolymer concentration.

525 Several cube specimens, made of silty sand and pure sand, were prepared and tested for the 526 unconfined compression accompanied by image processing. The surface of the cube specimens was 527 marked in a recognizable pattern before the testing. The testing process was recorded and 528 observed in an image processing software GOM Correlate. The strain development was tracked and 529 compared with calculated OSL. OSL appeared close to the peak stress, at which moment the image 530 processing software reported the initiation of the high strain concentrations. To capture more 531 precise strain distribution and bifurcation angles with the image processing software, a 3D image 532 acquisition and analysis should be performed. That approach requires more equipment and will be 533 utilized in future research.

534 In conclusion, the diagnostic strain analysis shows that the presence of biopolymers in the 535 soil can influence the onset of strain localization. Depending on the stress state, soil type, 536 biopolymer type, and concentration, the strain localization can be postponed or advanced. 537 Analyzing the complex mechanics of biopolymer-treated soil helps to understand the strength 
538 limitations of biopolymer treated soil. Understanding how biopolymers affect the strain localization

539 and failure of soil materials can lead to their utilization in engineering practice.

540

\section{DATA AVAILABILITY STATEMENT}

542 All data from this study can be provided by the corresponding author upon request. 


\section{REFERENCES}

547 ABAQUS FEA, 2019, Dassault Systèmes Simulia Corporation, Providence, RI, USA.

548 Aguilar, R., Nakamatsu, J., Ramírez, E., Elgegren, M., Ayarza, J., Kim, S., Pando, M.A., Ortega-San-

549 Martin, L., 2016. The potential use of chitosan as a biopolymer additive for enhanced 550 mechanical properties and water resistance of earthen construction. Construction and Building $551 \quad$ Materials 114, 625-637.

552 Andrew, R.M., 2018. Global CO2 emissions from cement production 23.

553 Ashraf, M.S., Azahar, S.B., Yusof, N.Z., 2017. Soil Improvement Using MICP and Biopolymers: A $554 \quad$ Review. IOP Conf. Ser.: Mater. Sci. Eng. 226, 012058.

555 Ayeldeen, M., Negm, A., El-Sawwaf, M., Kitazume, M., 2017. Enhancing mechanical behaviors of 556 collapsible soil using two biopolymers. Journal of Rock Mechanics and Geotechnical Engineering 5579 9, 329-339.

558 Bacic, A., Fincher, G.B., Stone, B.A., 2009. Chemistry, Biochemistry, and Biology of 1-3 Beta Glucans 559 and Related Polysaccharides. Academic Press.

560 Cabalar, A.F., Wiszniewski, M., Skutnik, Z., 2017. Effects of Xanthan Gum Biopolymer on the 561 Permeability, Odometer, Unconfined Compressive and Triaxial Shear Behavior of a Sand. Soil $562 \quad$ Mech Found Eng 54, 356-361.

563 Chang, I., Im, J., Cho, G.-C., 2016. Introduction of Microbial Biopolymers in Soil Treatment for Future 564 Environmentally-Friendly and Sustainable Geotechnical Engineering. Sustainability 8, 251.

565 Chang, I., Im, J., Prasidhi, A.K., Cho, G.-C., 2015a. Effects of Xanthan gum biopolymer on soil 566 strengthening. Construction and Building Materials 74, 65-72.

567 Chang, I., Prasidhi, A.K., Im, J., Cho, G.-C., 2015b. Soil strengthening using thermo-gelation 568 biopolymers. Construction and Building Materials 77, 430-438. 
569 Chen, R., Zhang, L., Budhu, M., 2013. Biopolymer Stabilization of Mine Tailings. J. Geotech. $570 \quad$ Geoenviron. Eng. 139, 1802-1807.

571 Choi, S.-G., Wang, K., Chu, J., 2016. Properties of biocemented, fiber reinforced sand. Construction $572 \quad$ and Building Materials 120, 623-629.

573 Das, B.M., 2019. Advanced Soil Mechanics, Fifth Edition. CRC Press.

574 Deniz Akin, I., Likos, W.J., 2017. Brazilian Tensile Strength Testing of Compacted Clay. Geotech. Test. $575 \quad$ J. 40, 20160180.

576 DeJong, J.T., Mortensen, B.M., Martinez, B.C., Nelson, D.C., 2010. Bio-mediated soil improvement. 577 Ecological Engineering 36, 197-210.

578 Gom Correlate, 2020, Knucklehead Productions, Trilion Quality Systems, King of Prussia, PA, USA

579 Gombotz, W.R., Wee, S.F., 2012. Protein release from alginate matrices. Advanced Drug Delivery $580 \quad$ Reviews 64, 194-205.

581 Hirai, H., Takahashi, M. and Yamada, M., 1989. An elastic-plastic constitutive model for the behavior 582 of improved sandy soils. Soils and foundations, 29(2), pp.69-84.

583 Izzo, M.Z., Miletić, M., 2019. Sustainable Improvement of the Crack Resistance of Cohesive Soils. $584 \quad$ Sustainability $11,5806$.

585 Katzbauer, B., 1998. Properties and applications of xanthan gum. Polymer degradation and Stability $586 \quad 59,81-84$.

587 Kutanaei, S.S., Choobbasti, A.J., 2016. Triaxial behavior of fiber-reinforced cemented sand. Journal of $588 \quad$ Adhesion Science and Technology 30, 579-593.

589 Lee, K.Y., Mooney, D.J., 2012. Alginate: Properties and biomedical applications. Progress in Polymer $590 \quad$ Science 37, 106-126.

591 Li, L., Cetin, B., Yang, X., 2018. Proceedings of GeoShanghai 2018 International Conference: Ground $592 \quad$ Improvement and Geosynthetics. Springer. 
593 Liu, C., Tang, C.-S., Shi, B., Suo, W.-B., 2013. Automatic quantification of crack patterns by image 594 processing. Computers \& Geosciences 57, 77-80.

595 Miletić, M., 2016. Modeling of Localized Deformation in High and Ultra-High Performance Fiber 596 Reinforced Cementitious Composites. PhD. Dissertation, Kansas State University.

597 Miletić, M., Perić, D., 2018. Effect of Fibers on the Onset of Strain Localization in HPFRCC Subjected 598 to Plane Stress Loading. Journal of Engineering Mechanics 144(9): 04018074.

599 Ottosen, N.S., Runesson, K., 1991. Properties of discontinuous bifurcation solutions in elasto$600 \quad$ plasticity. International Journal of Solids and Structures 27, 401-421.

601 Rahimi, M., Chan, D. and Nouri, A., 2016. Bounding surface constitutive model for cemented sand 602 under monotonic loading. International Journal of Geomechanics, 16(2), p.04015049.

603 Schnaid, F., Prietto, P.D.M., Consoli, N.C., 2001. Characterization of Cemented Sand in Triaxial 604 Compression. J. Geotech. Geoenviron. Eng. 127, 857-868.

605 Shit, P.K., Bhunia, G.S., Maiti, R., 2015. Soil crack morphology analysis using image processing 606 techniques. Model. Earth Syst. Environ. 1, 35.

607 Soldo, A. and Miletić, M., 2019. Study on Shear Strength of Xanthan Gum-Amended Soil. 608 Sustainability, 11(21), p.6142.

609 Soldo, A., Miletić, M. and Auad, M.L., 2020. Biopolymers as a sustainable solution for the 610 enhancement of soil mechanical properties. Scientific Reports, 10(1), pp.1-13.

611 Strömblad, N., n.d. Modeling of Soil and Structure Interaction Subsea 70. 2014

612 Tagliaferri, F., Waller, J., Andò, E., Hall, S.A., Viggiani, G., Bésuelle, P., DeJong, J.T., 2011. Observing 613 strain localisation processes in bio-cemented sand using x-ray imaging. Granular Matter 13, $614 \quad 247-250$.

615 Thombare, N., Jha, U., Mishra, S., Siddiqui, M.Z., 2016. Guar gum as a promising starting material for 616 diverse applications: A review. International Journal of Biological Macromolecules 88, 361-372. 
617 Toufigh, V., Kianfar, E., 2019. The effects of stabilizers on the thermal and the mechanical properties 618 of rammed earth at various humidities and their environmental impacts. Construction and $619 \quad$ Building Materials 200, 616-629.

620 Truty, A. and Obrzud, R., 2011. The Hardening soil model-a practical guidebook. Zace Services Ltd, 621 Software engineering. Lausanne.

622 Umar, M., Kassim, K.A., Ping Chiet, K.T., 2016. Biological process of soil improvement in civil 623 engineering: A review. Journal of Rock Mechanics and Geotechnical Engineering 8, 767-774.

624 Volman, J.J., Ramakers, J.D., Plat, J., 2008. Dietary modulation of immune function by $\beta$-glucans. 625 Physiology \& Behavior 94, 276-284.

626 Wattrisse, B., Chrysochoos, A., Muracciole, J.-M., Némoz-Gaillard, M., 2001. Analysis of strain 627 localization during tensile tests by digital image correlation. Experimental Mechanics 41, 29-39. 628 Wiszniewski, M., Skutnik, Z., Biliniak, M., Çabalar, A.F., 2017. Some geomechanical properties of a 629 biopolymer treated medium sand. Annals of Warsaw University of Life Sciences - SGGW. Land $630 \quad$ Reclamation 49, 201-212.

631 ASTM D2166/D2166M-13, Standard Test Method for Unconfined Compressive Strength of Cohesive 632 Soil. 1-7 (2016).

633 ASTM D3967-16, Standard Test Method for Splitting Tensile strength of Intact Rock Core $634 \quad$ Specimens. 1-5 (2016).

635 ASTM D2850-15, Standard Test Method for Unconsolidated-Undrained Triaxial Compression Test 636 on Cohesive Soils. 1-7 (2015).

637 ASTM D6913-17, Standard Test Methods for Particle-Size Distribution (Gradation) of Soils Using 638 Sieve Analysis. 1-34 (2017).

639 ASTM D4318-17, Standard Test Methods for Liquid Limit, Plastic Limit, and Plasticity Index of Soils.. $640 \quad 1-20(2017)$

641 
643 Fig. 1. The example of the calibration procedure for the silty sand with 4\% BG

644 Fig. 2. Hardening response for the unconfined compression test for silty sand treated with BG

645 Fig. 3. Unconfined compression test results of the silty sand with a)0\% additives; b) 1\% BG; c) 2\% 646 BG; d) $4 \%$ BG

647 Fig. 4. Unconfined compression test results of the silty sand with a) $0 \%$ additives; b) 1\% GG; c) $2 \%$

648 GG; d) $4 \%$ GG

649 Fig. 5. Unconfined compression test results of the silty sand with a)0\% additives; b) 1\% XG; c) $2 \%$ 650 XG; d) $4 \%$ XG

651 Fig. 6. Unconfined compression test results: a) axial strain at OSL and b) axial stress at OSL for the 652 unconfined compression test of silty sand

653 Fig. 7. Bifurcation angle for the plain and biopolymer-treated silty sand (unconfined compression 654 test)

655 Fig. 8. Unconsolidated undrained triaxial test results a) axial stress at OSL; b) axial strain at OSL; c)

656 bifurcation angle

657 Fig. 9. Comparing unconfined compression test (UC) with the triaxial test (UU) for the plain silty 658 sand and silty sand treated with a) XG; b) GG; c) BG

659 Fig. 10. Image processing of strain localization for sand with a) $0.5 \%$ XG and b) $1 \%$ XG under 660 unconfined compression test compared with the numerically obtained OSL and experimental data

661 Fig. 11. Image processing of strain localization for the silty sand with a) no additives; b) $0.5 \%$ XG;

662 c) $1 \%$ GG under unconfined compression test compared with the numerically obtained OSL and 663 experimental data

664 Table 1. Selected properties of the biopolymer-treated soil for the proposed model 


\section{Unconfined compression test}

\section{Splitting tensile strength test}

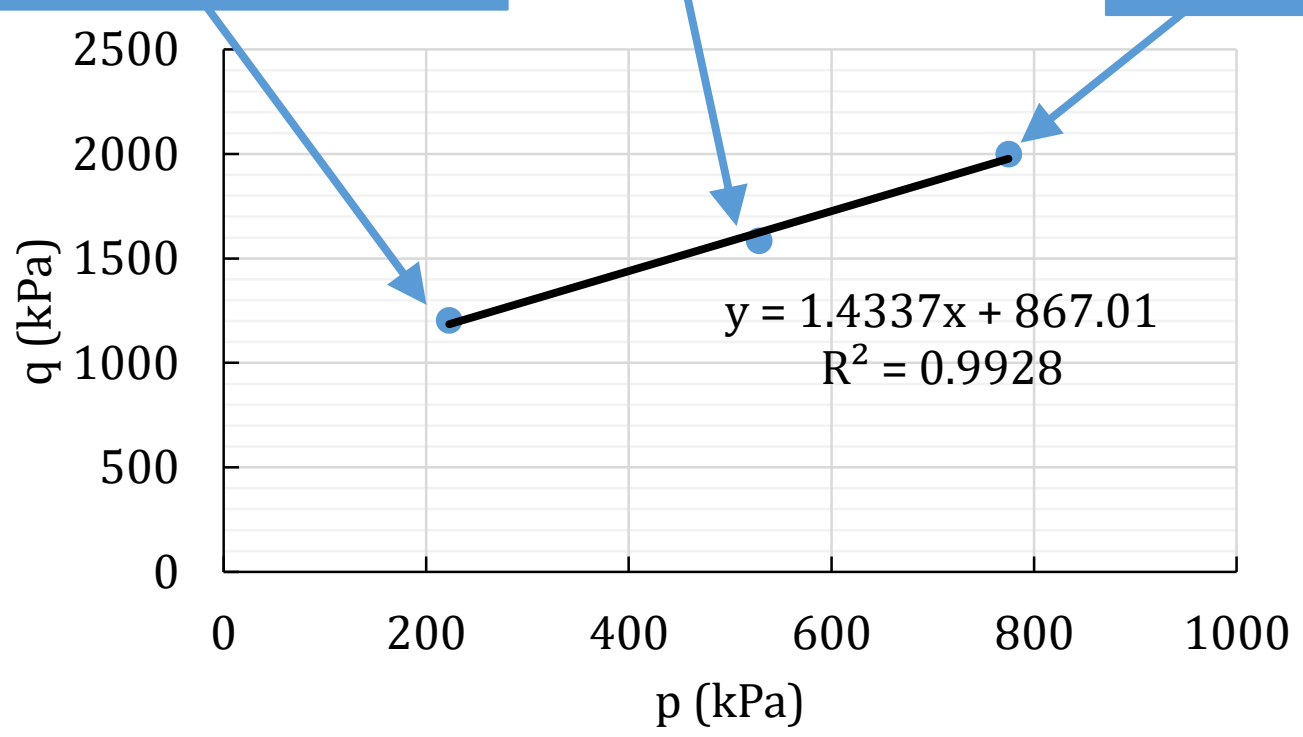

\section{Triaxial test}




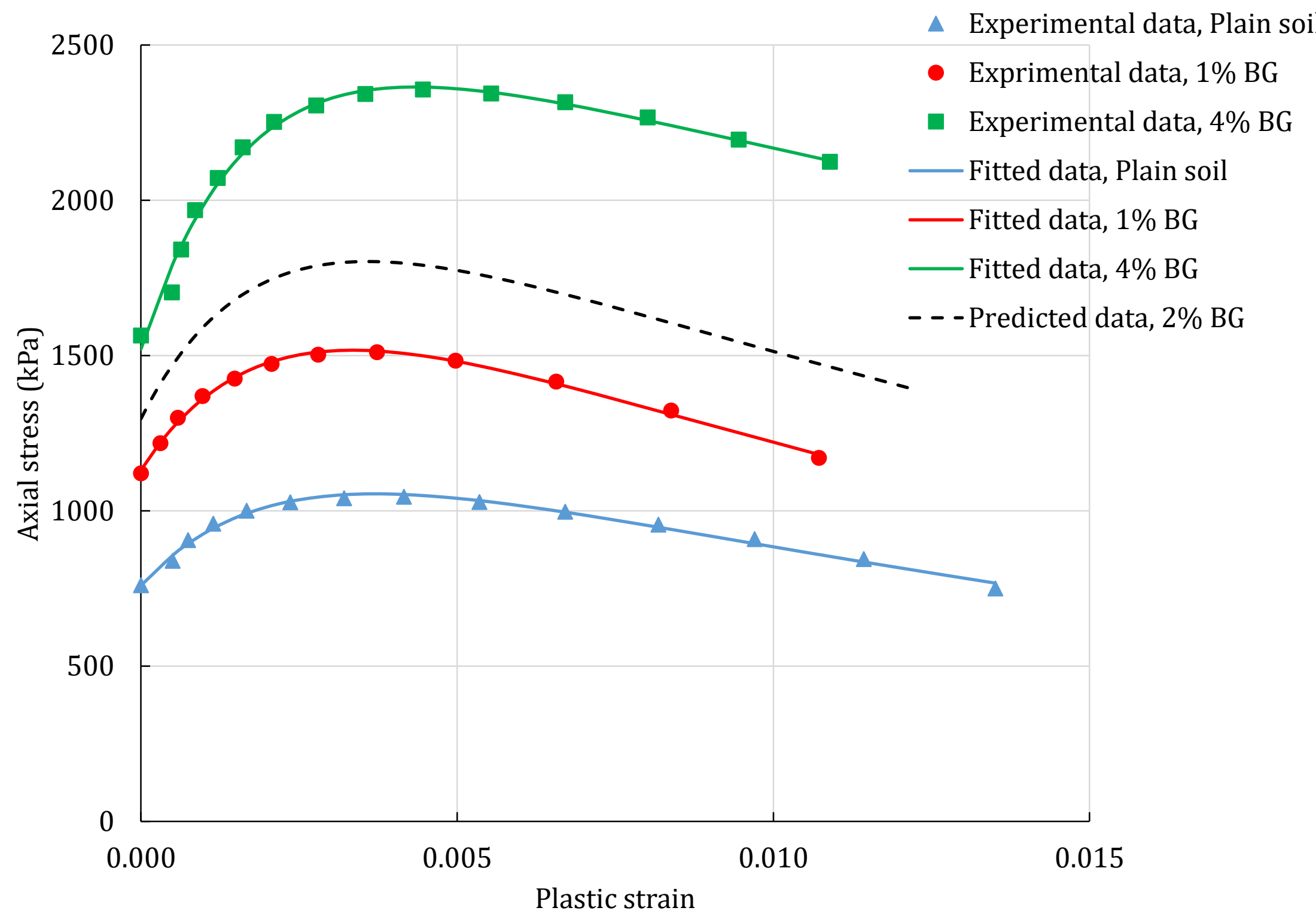




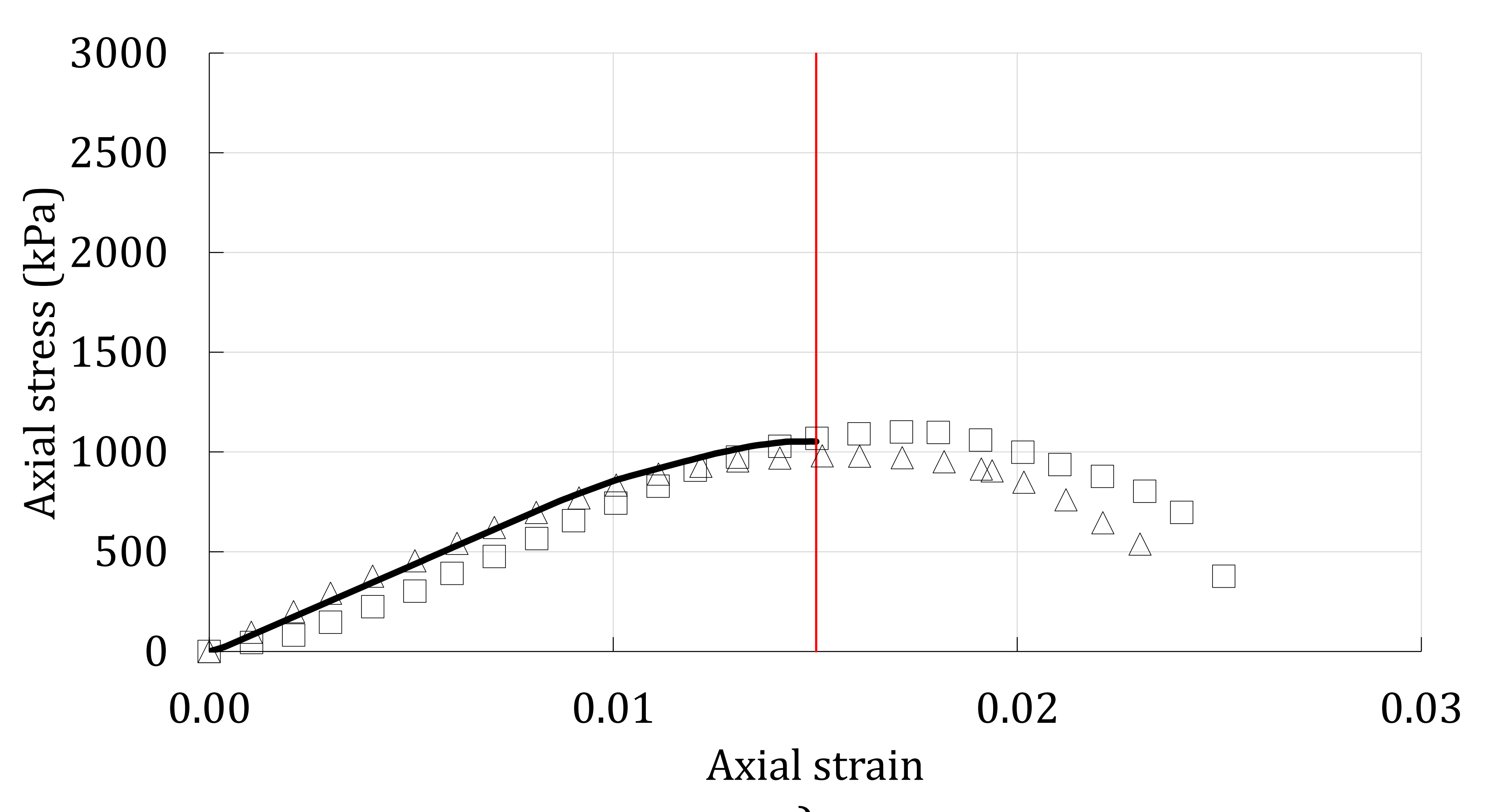

a)

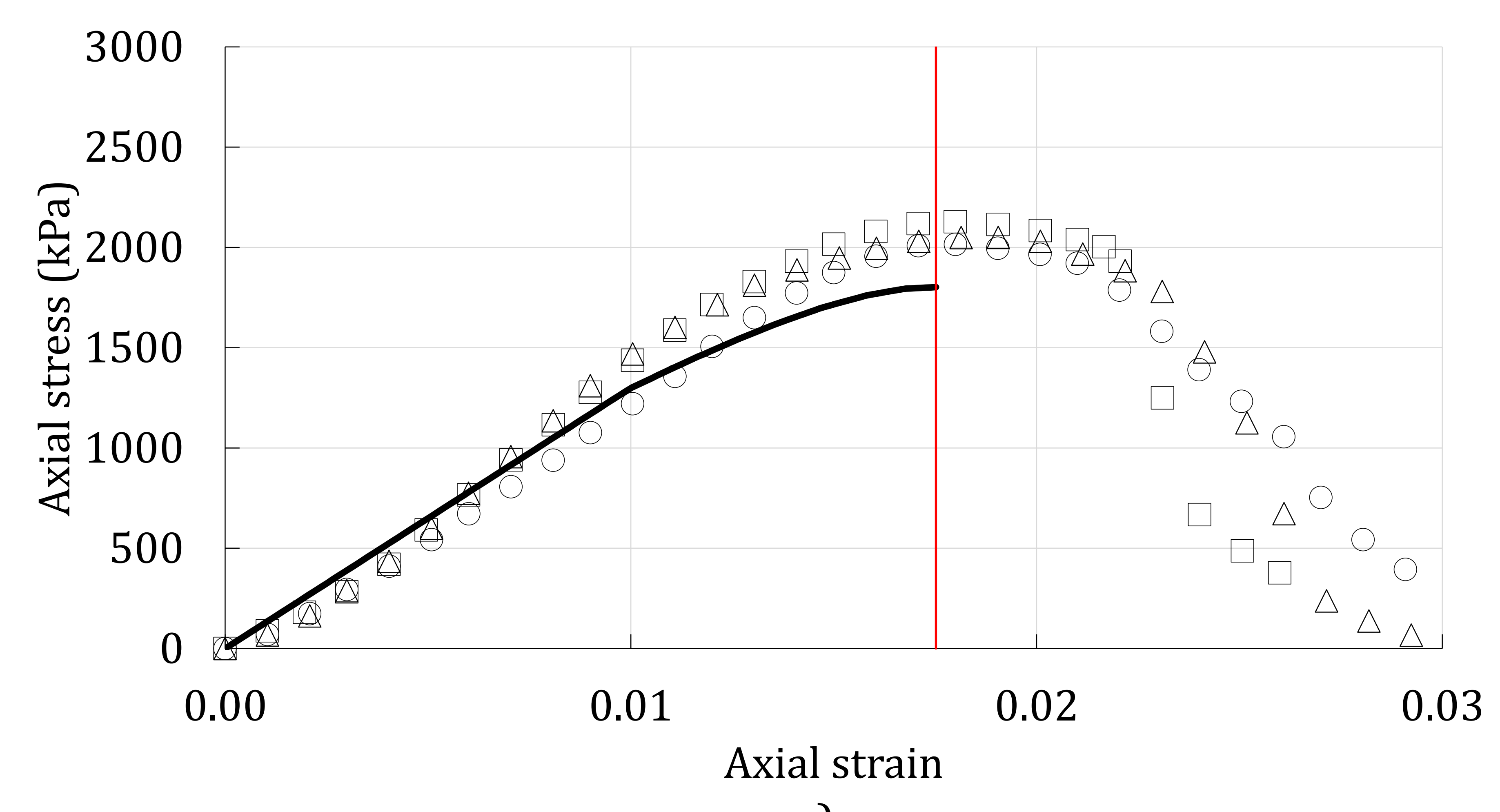

c)

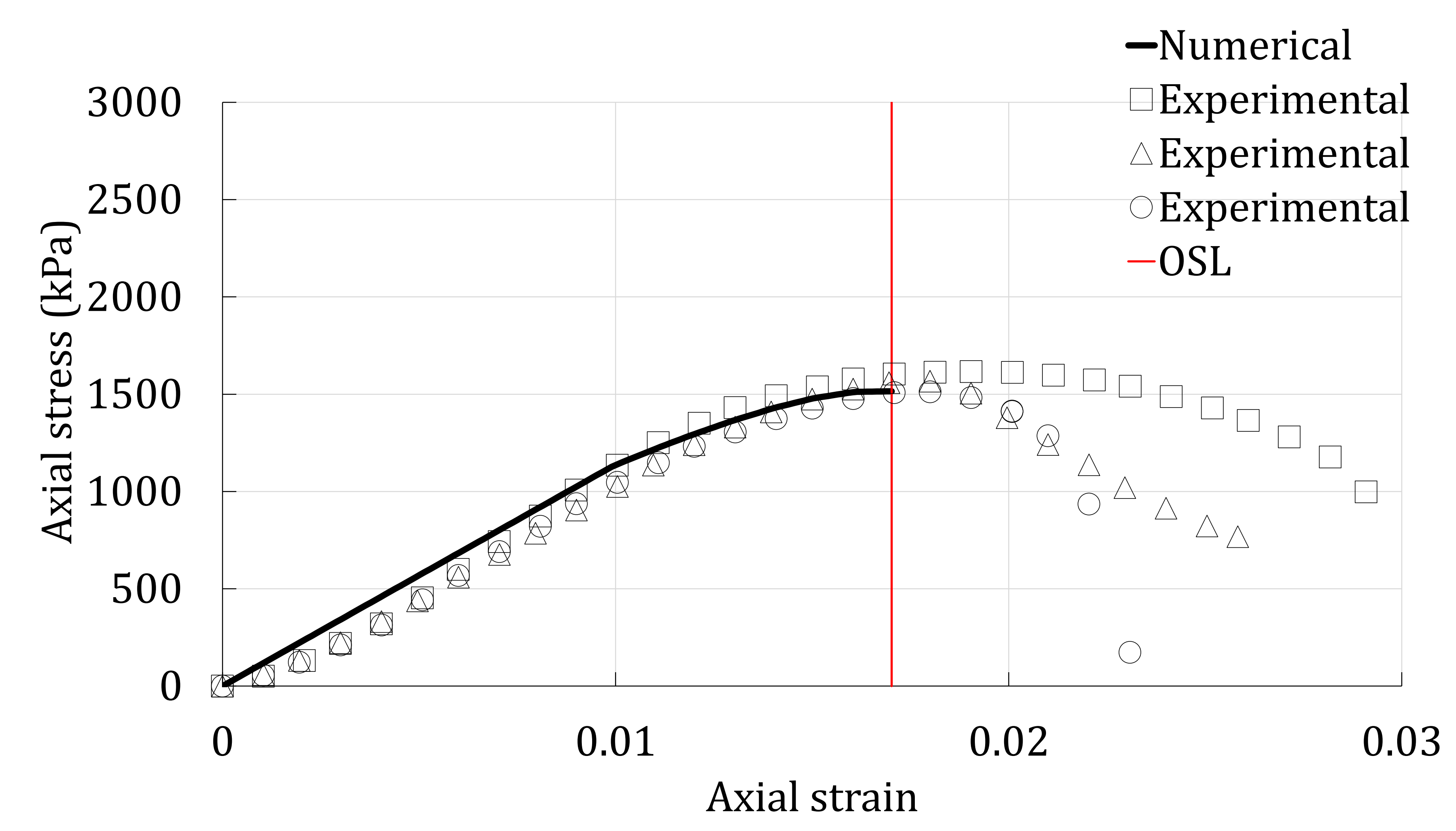

b)

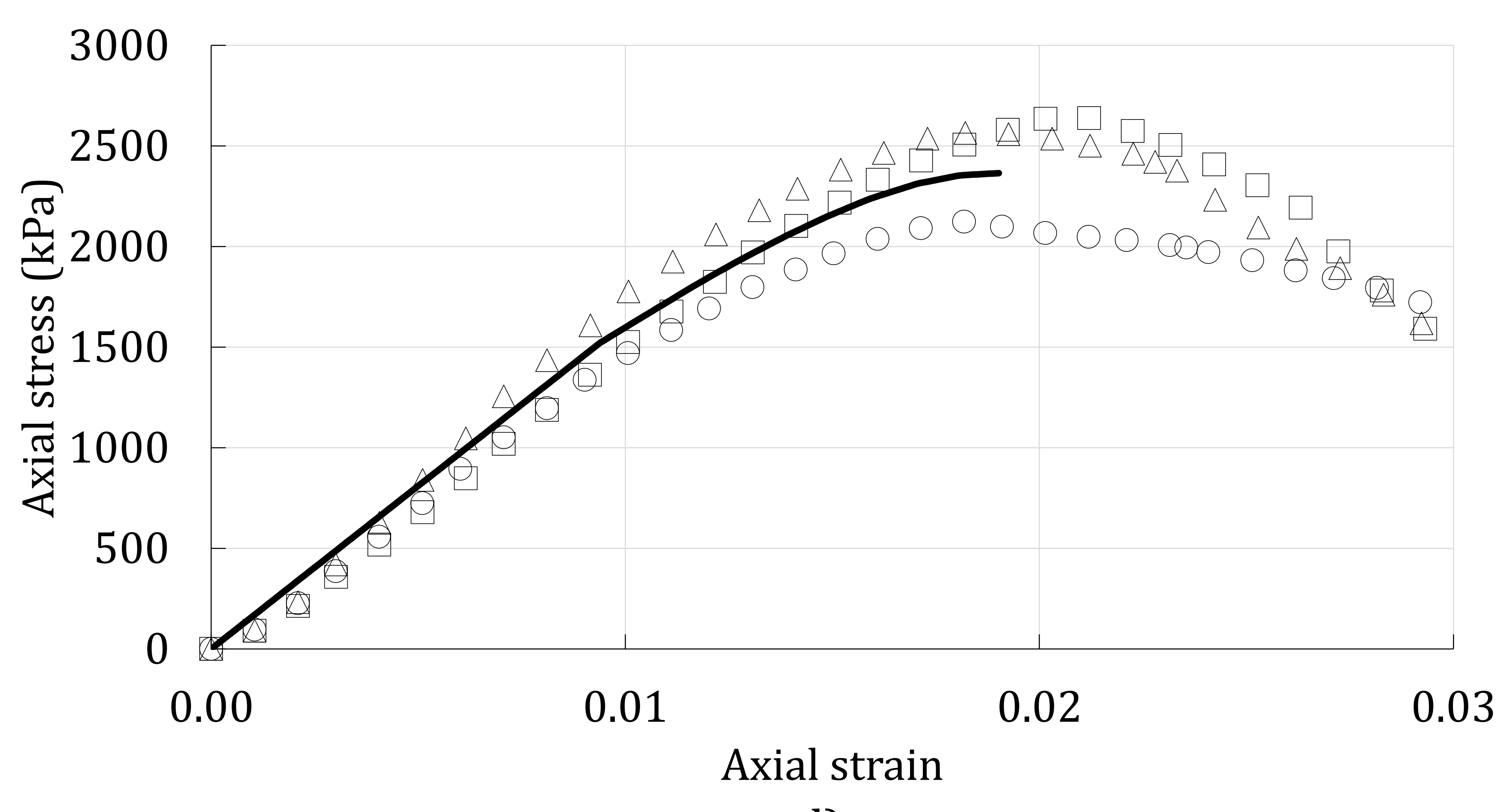

d) 


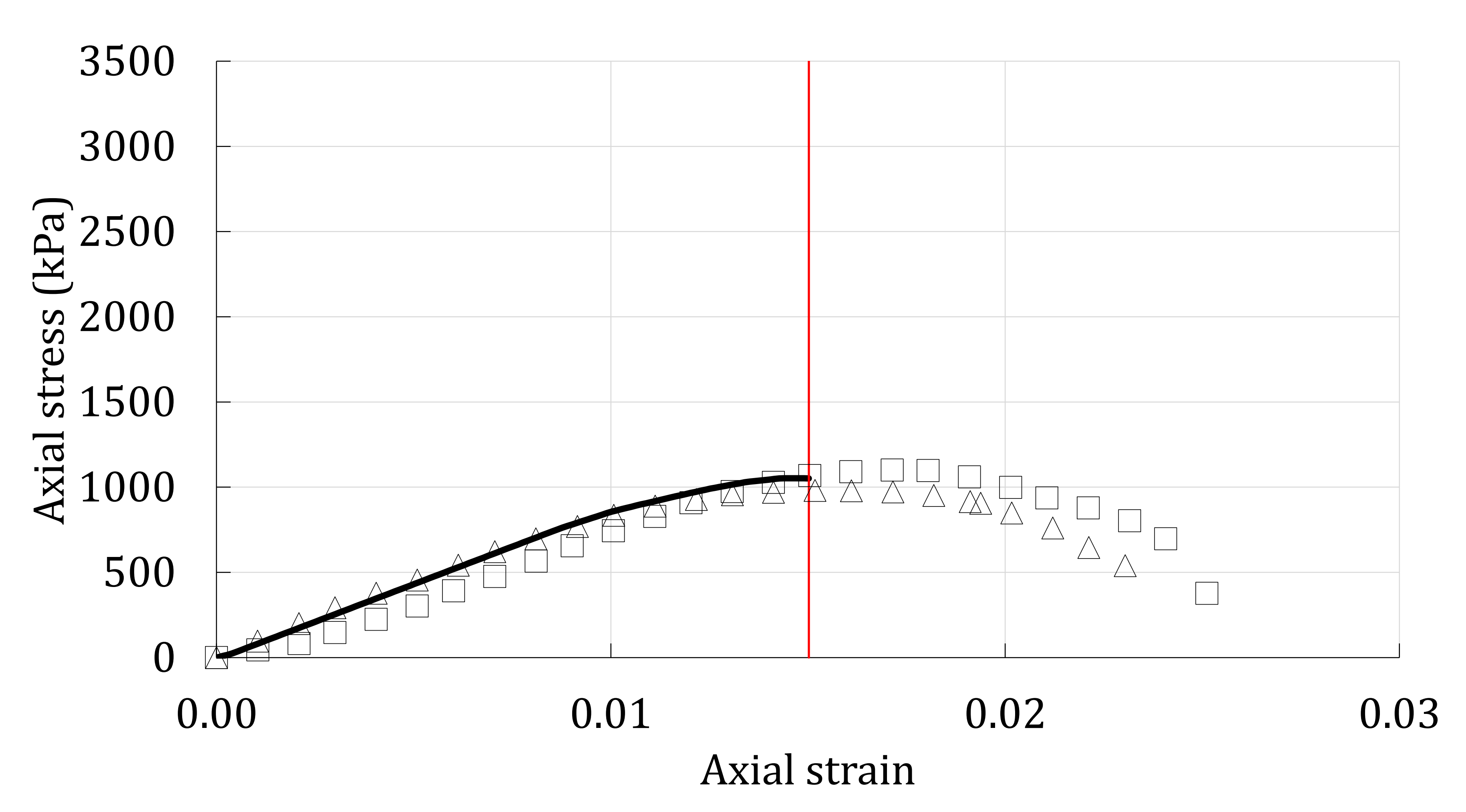

a)

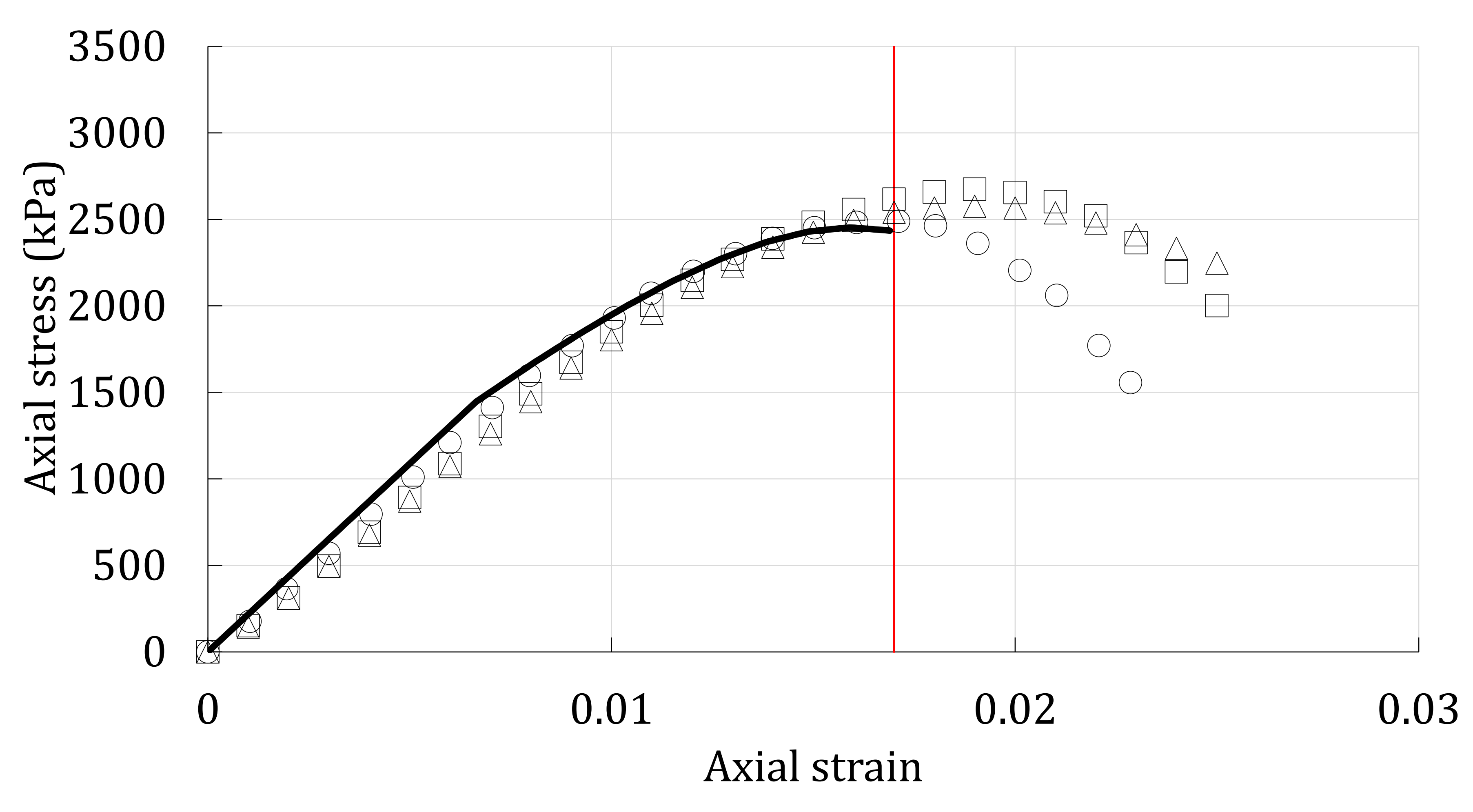

c)

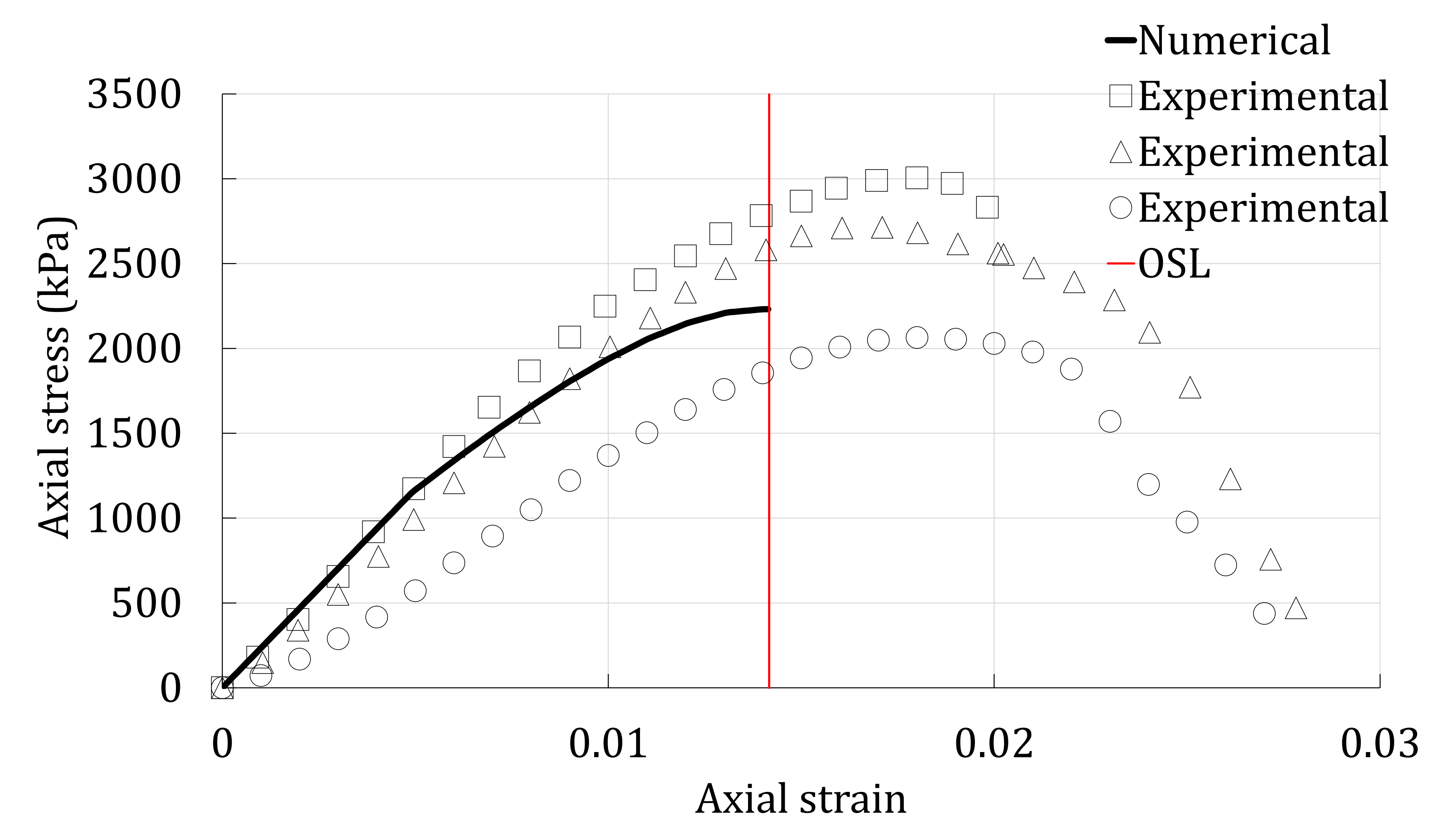

b)

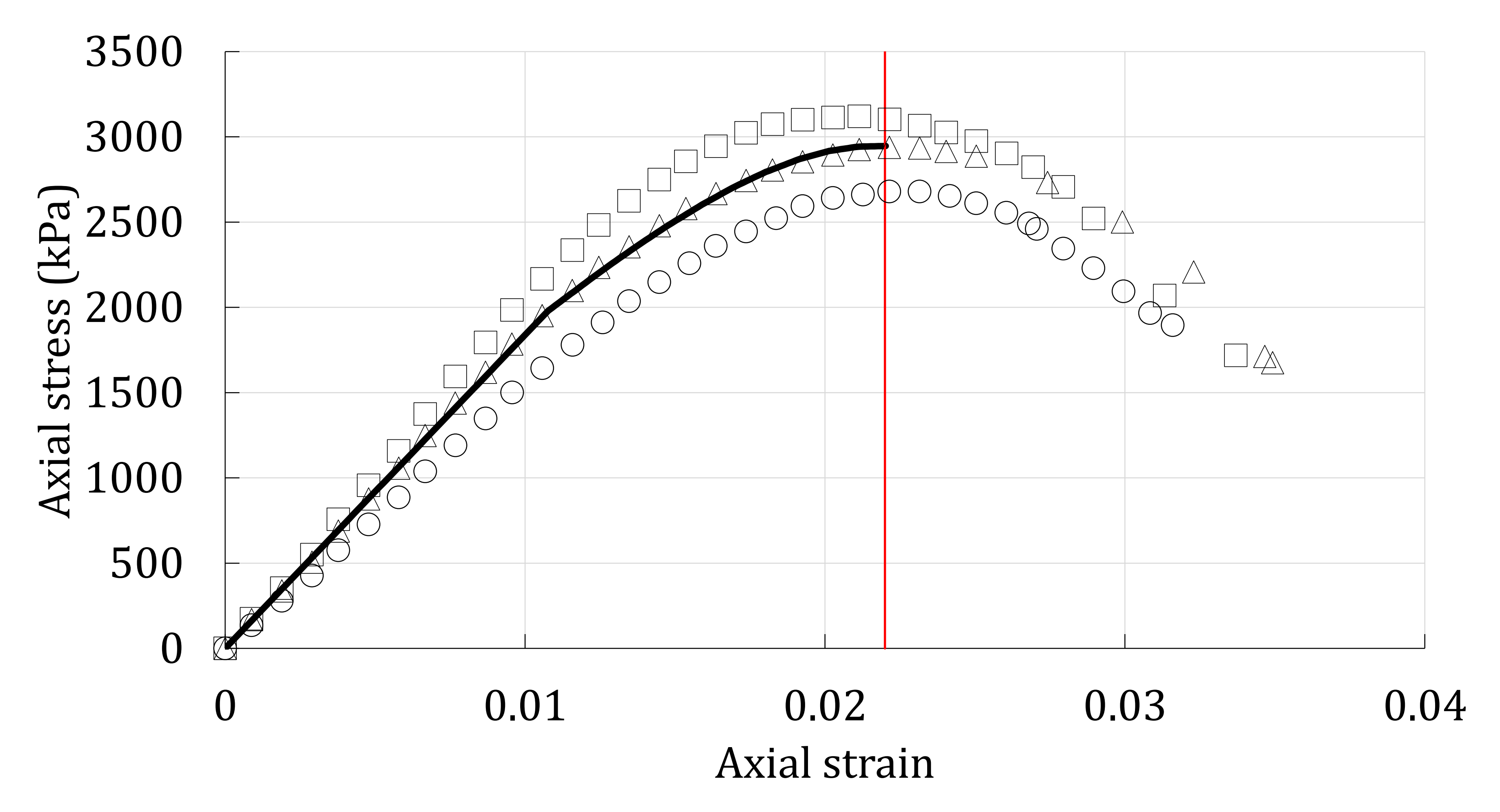

d) 


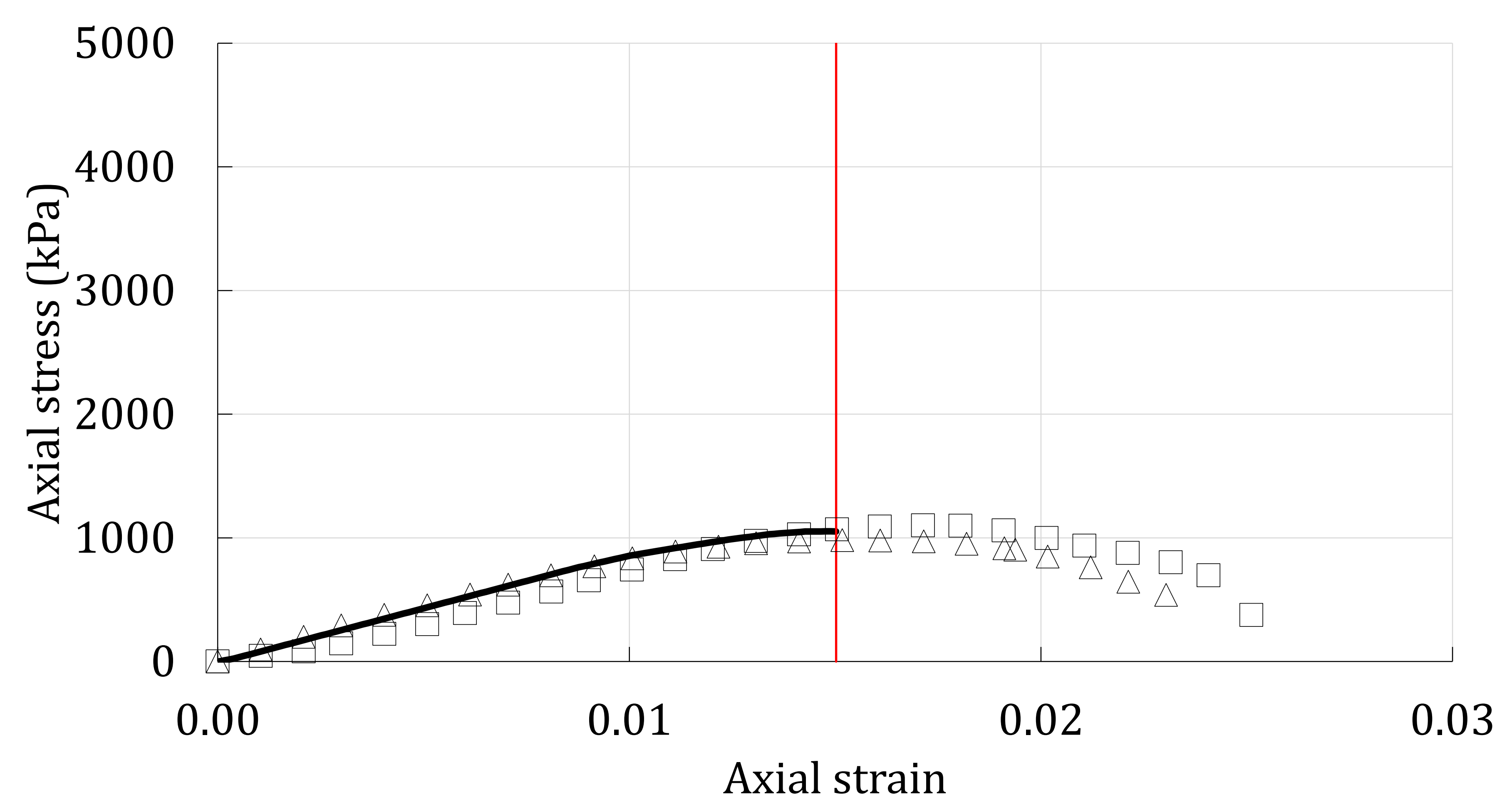

a)

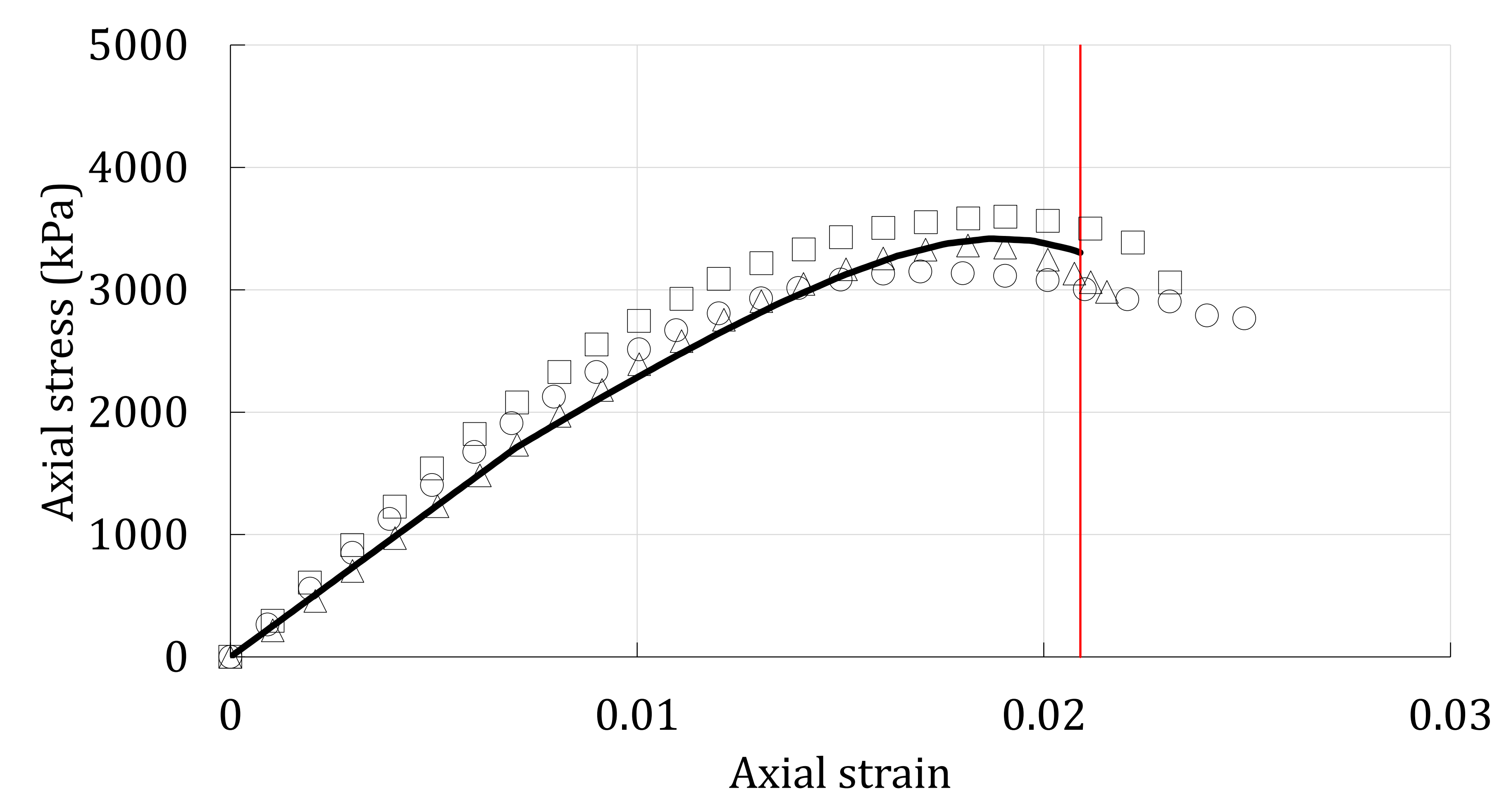

c)

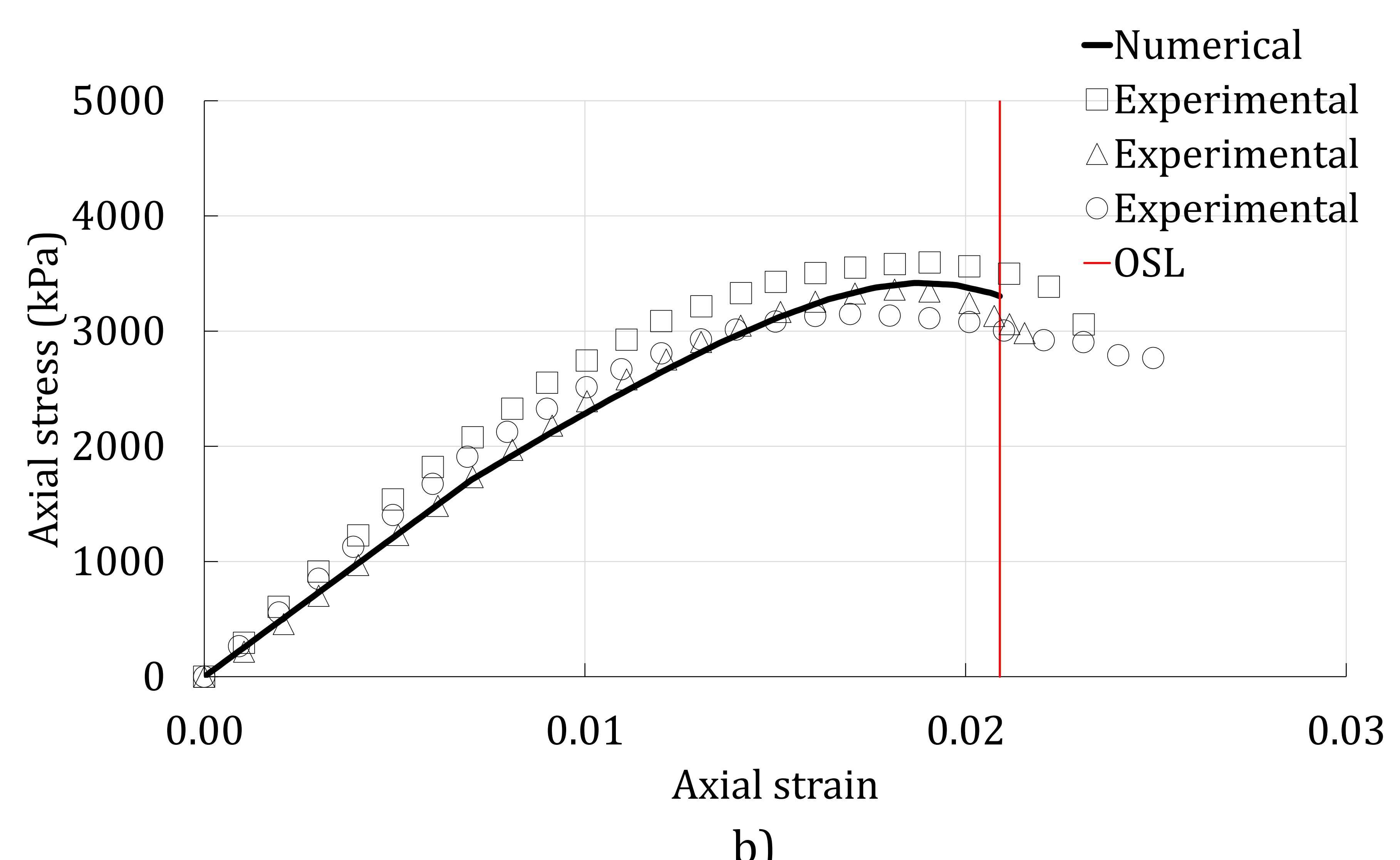

b)

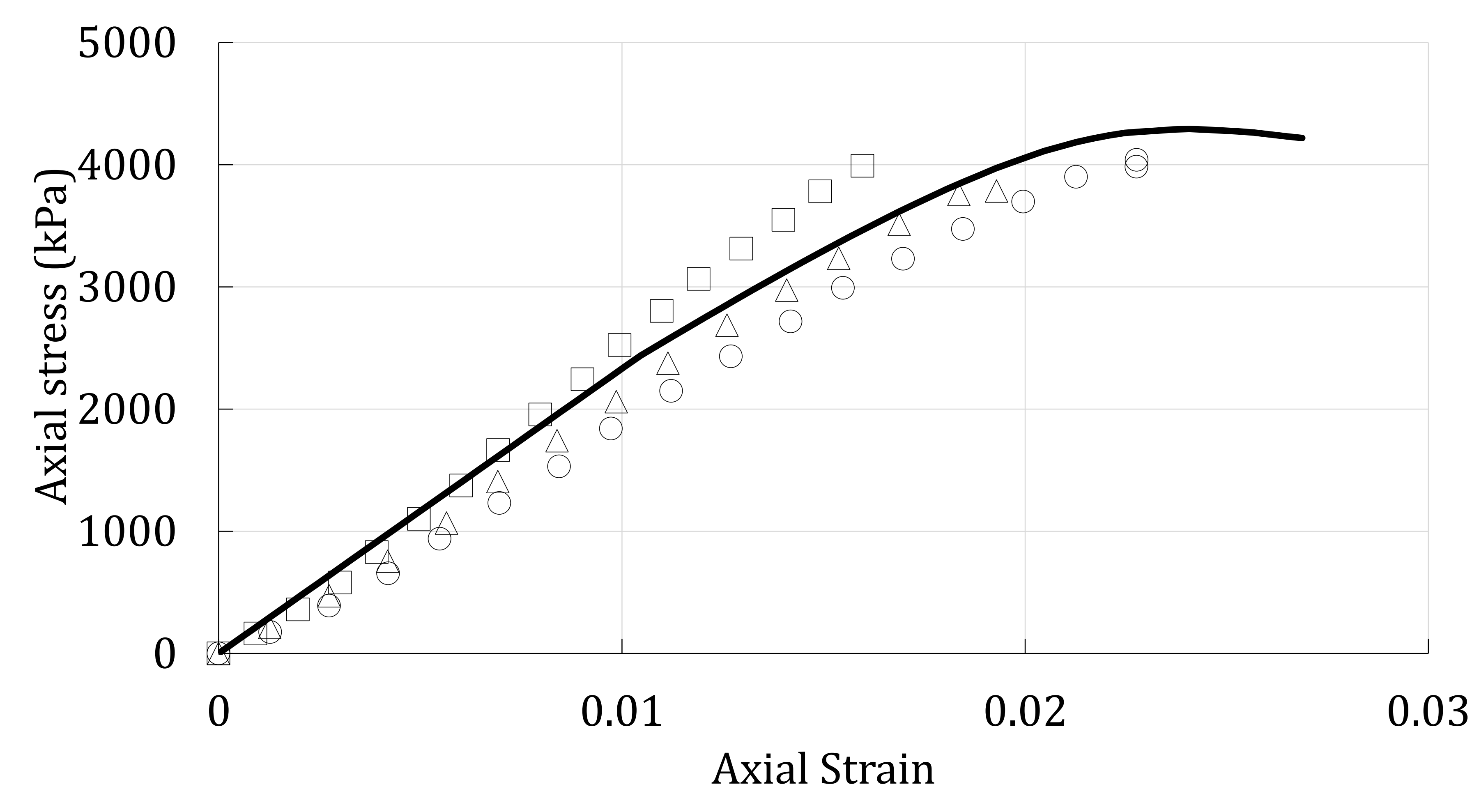

d) 


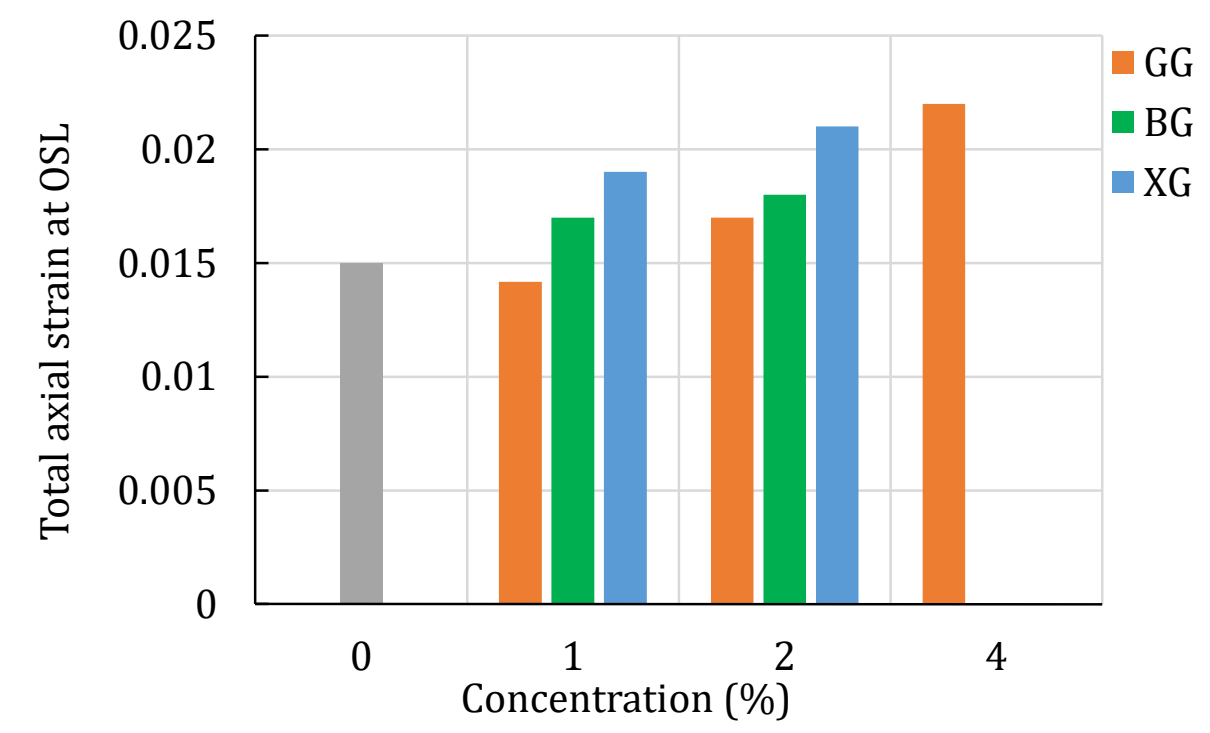

a)

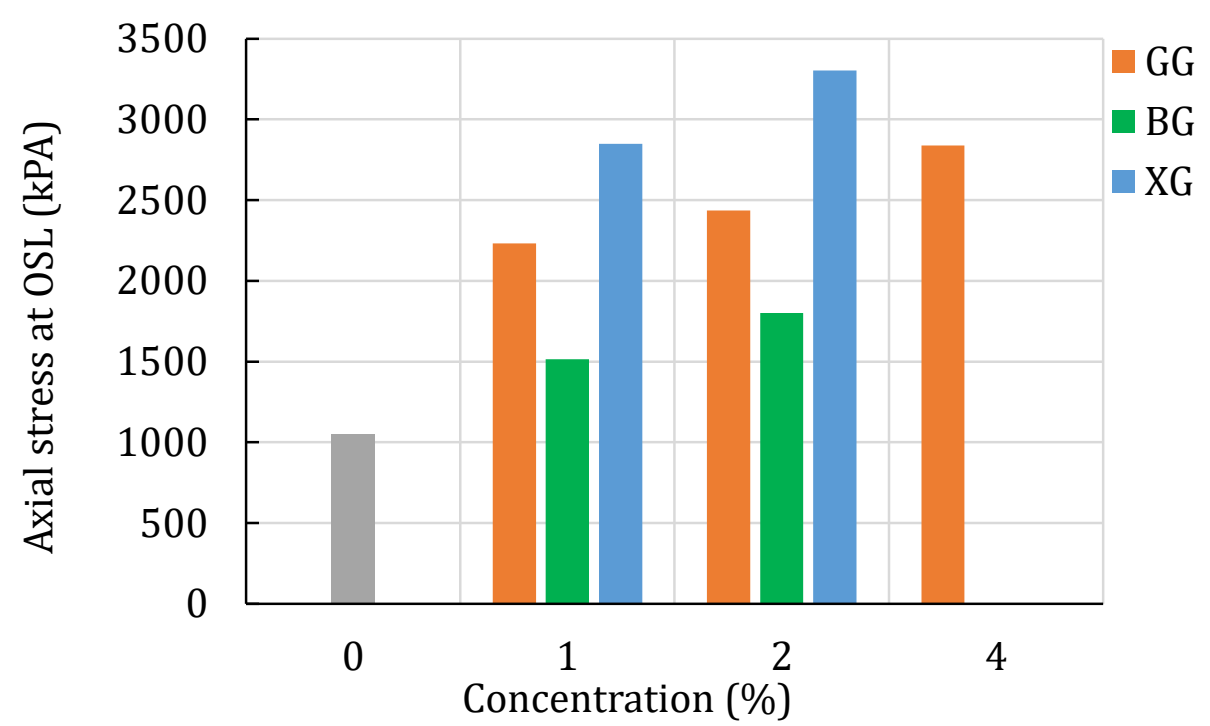

b) 


\section{Bifrucation angle $\left({ }^{\circ}\right)$}

$\circ$ ○

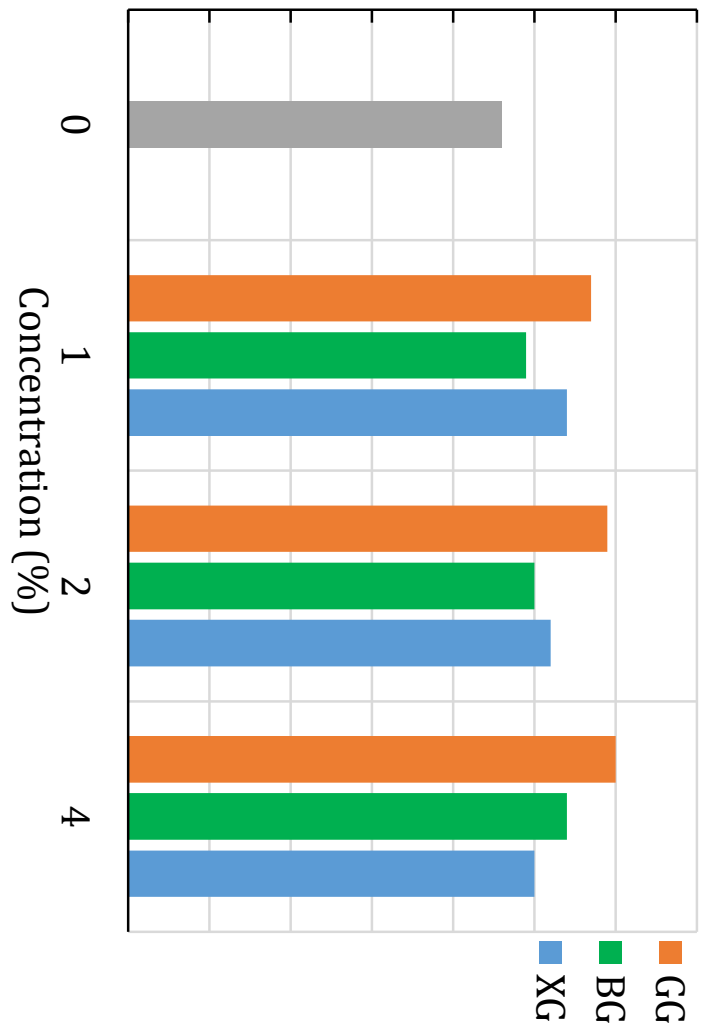




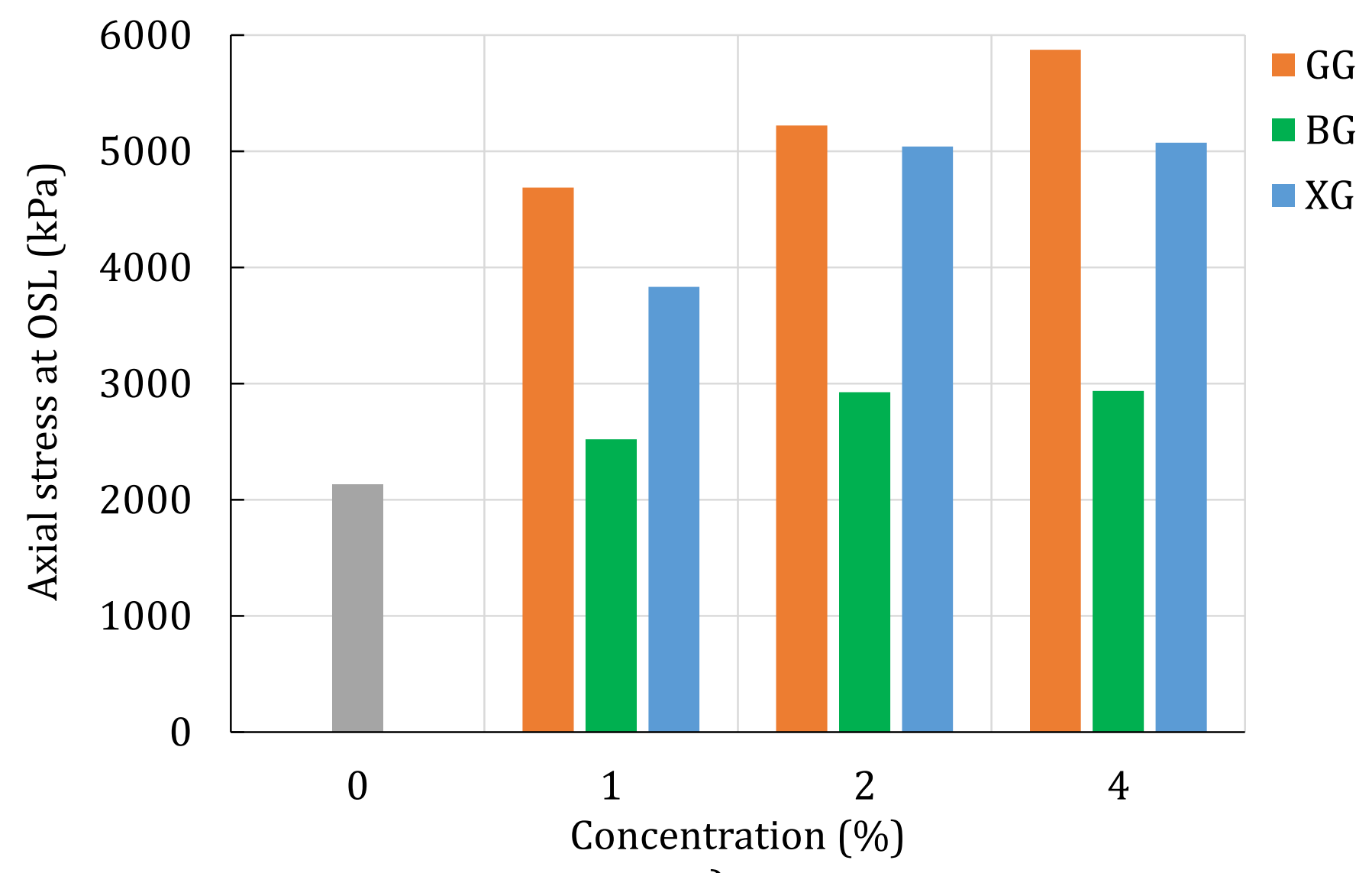

a)

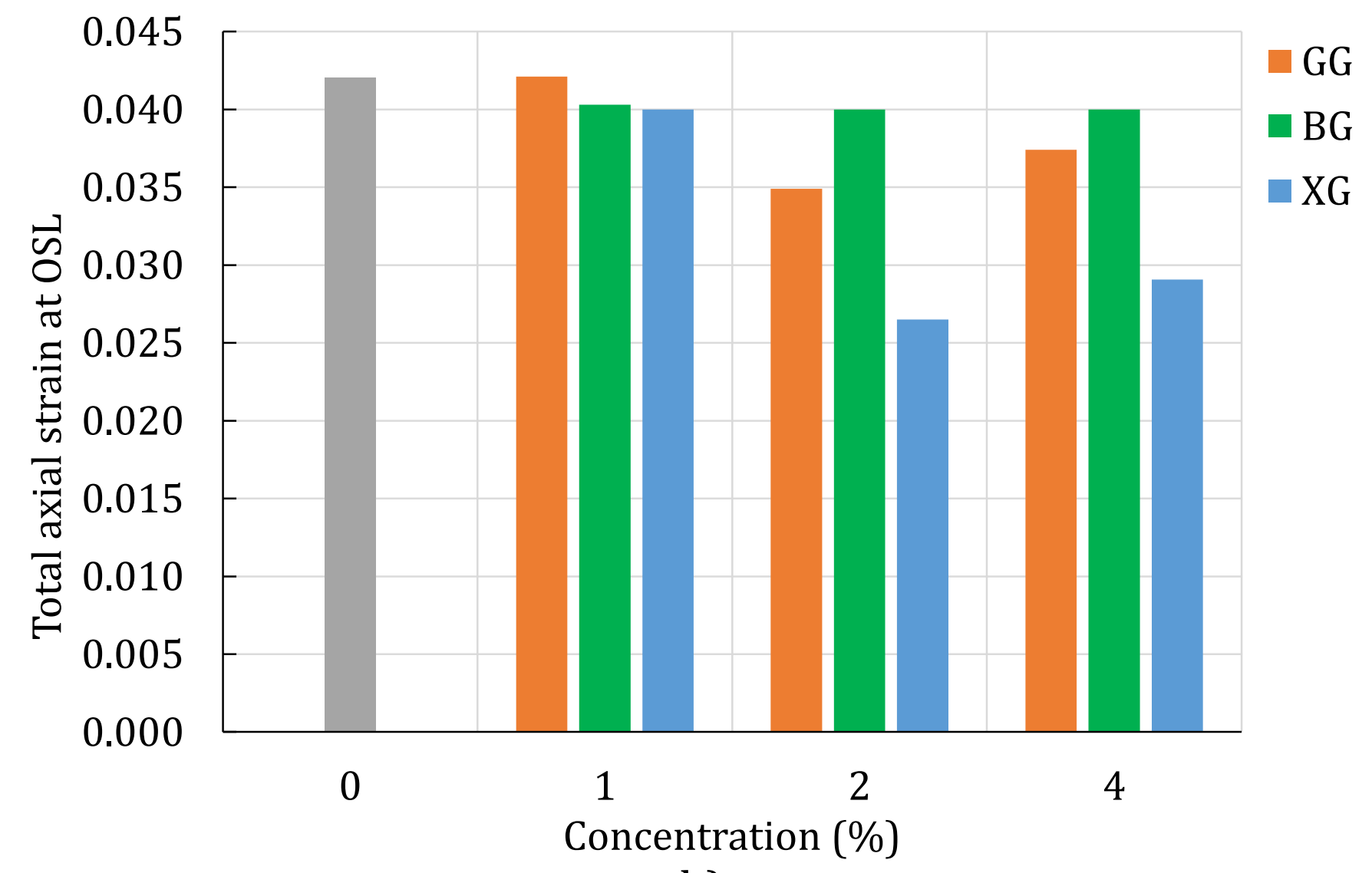

b)

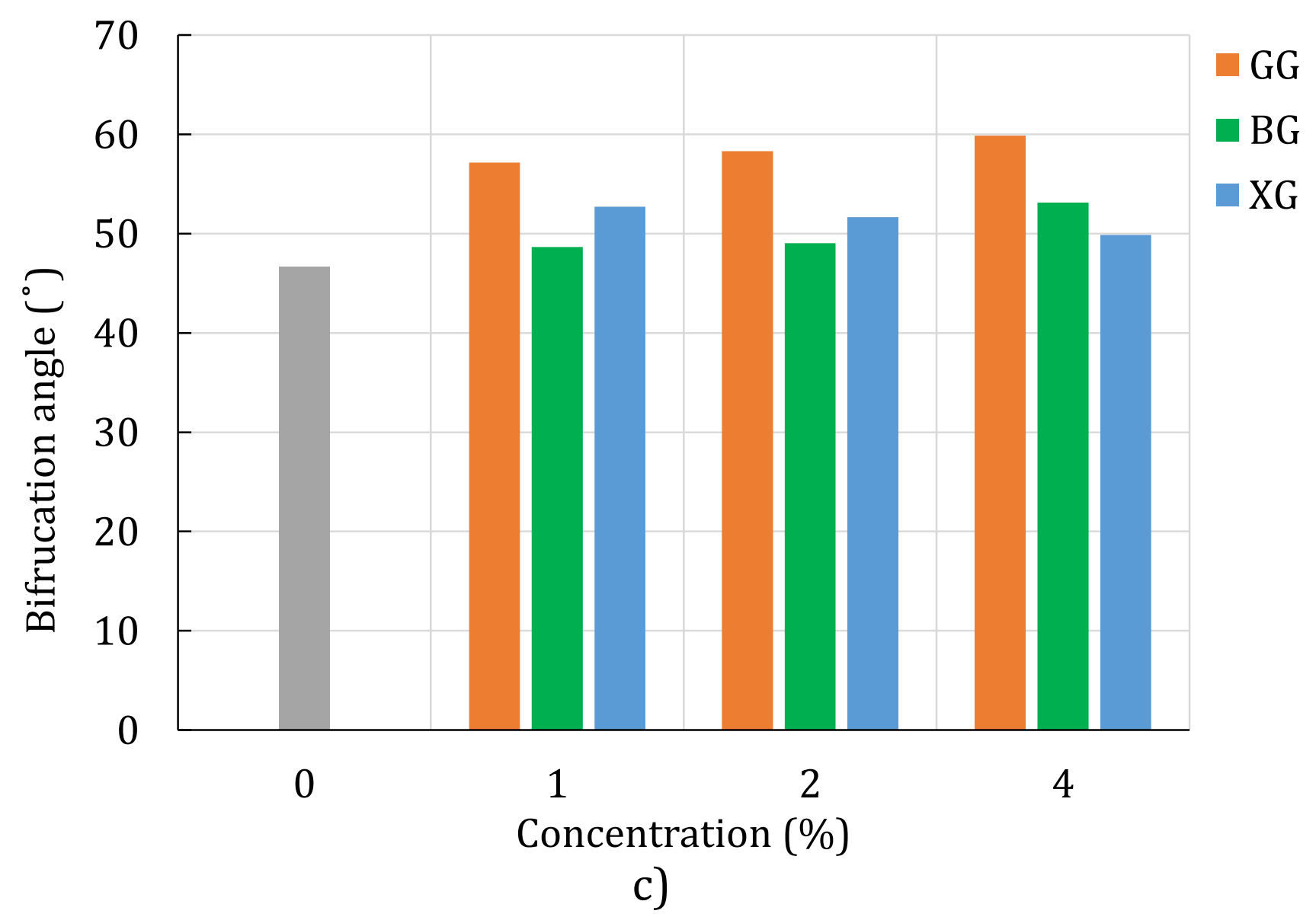




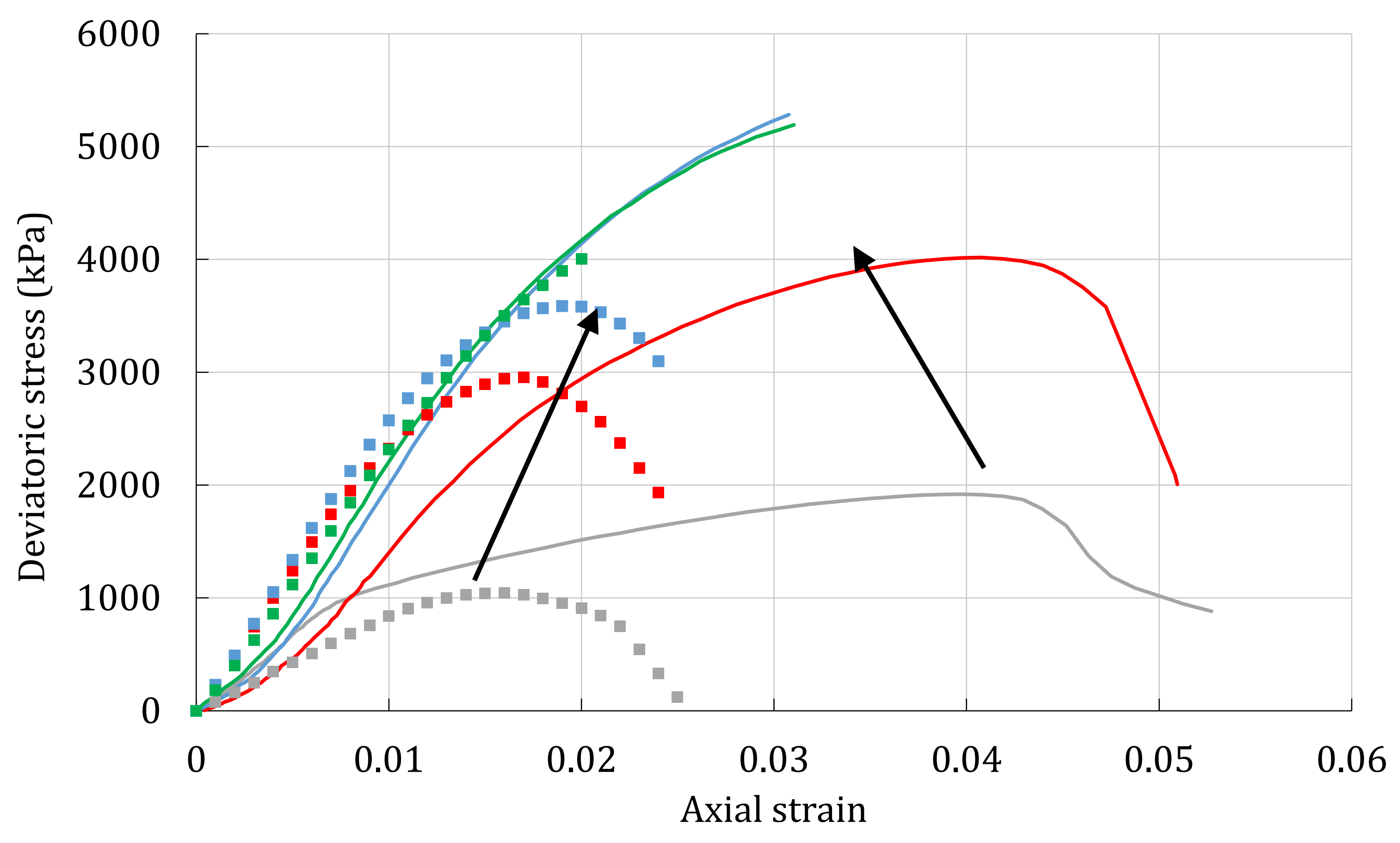

a)

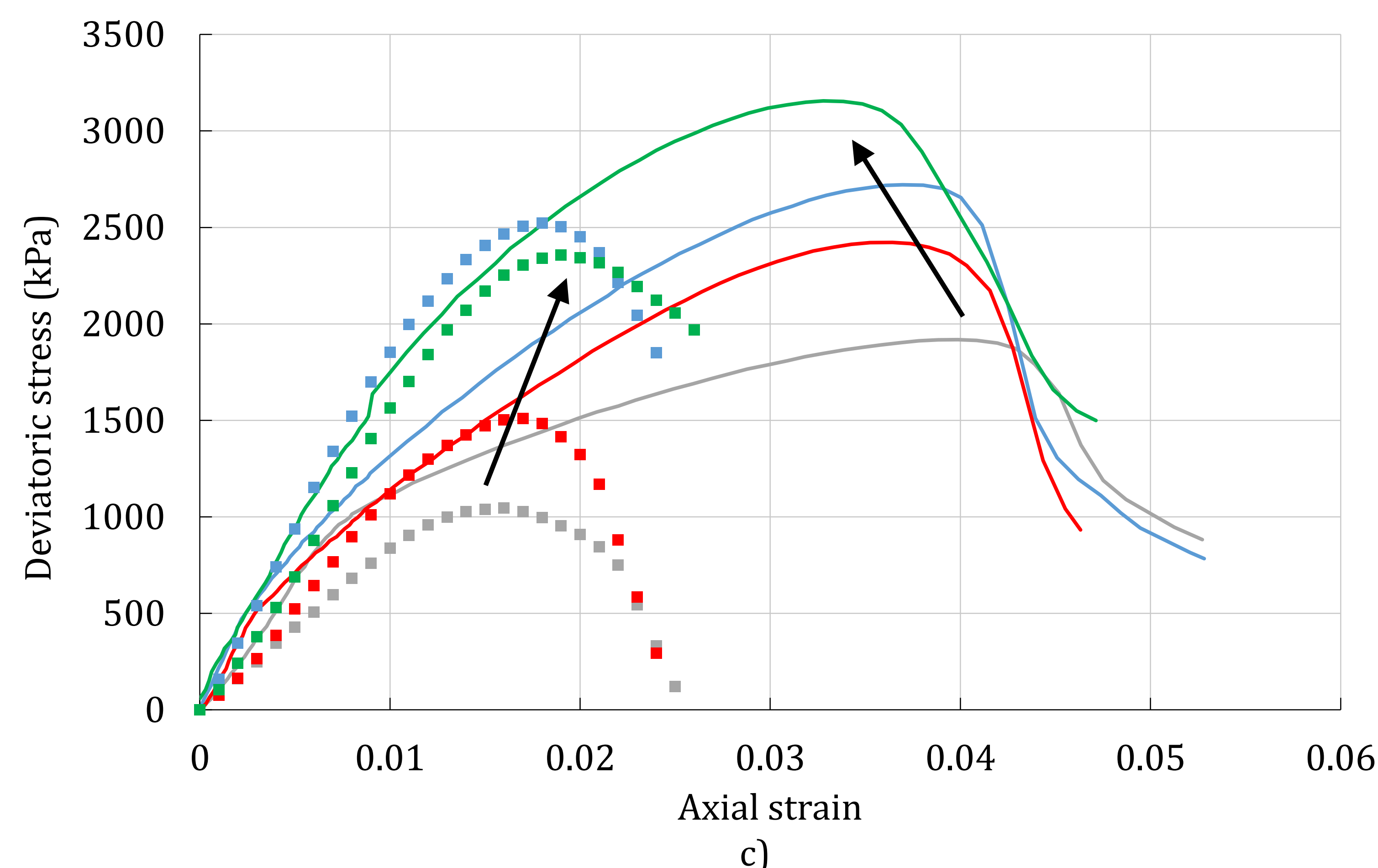

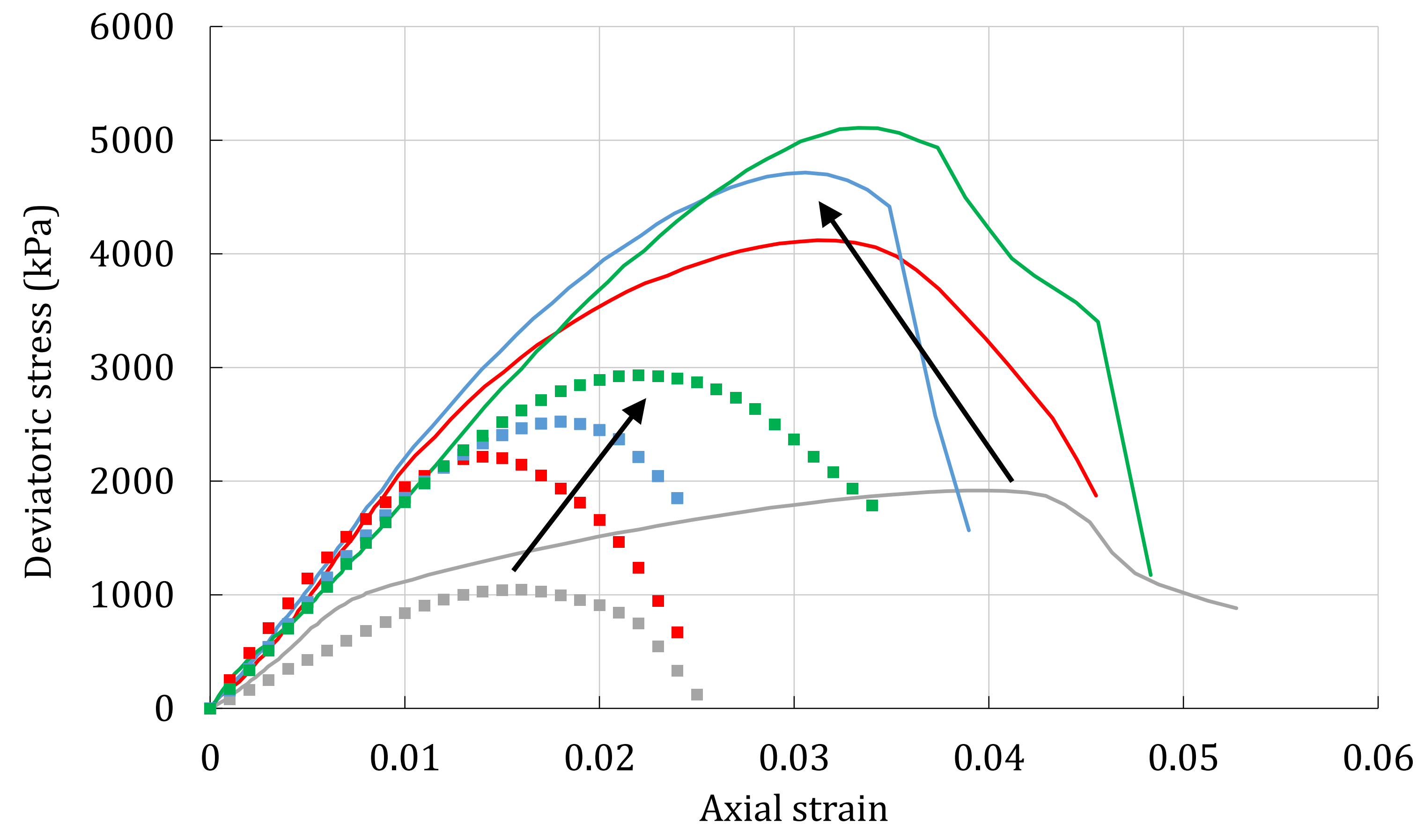

b)

- Plain UC -Plain UU

- $1 \%$ UC $-1 \%$ UU

- $2 \% \mathrm{UC}-2 \% \mathrm{UU}$

- $4 \%$ UC $-4 \%$ UU 

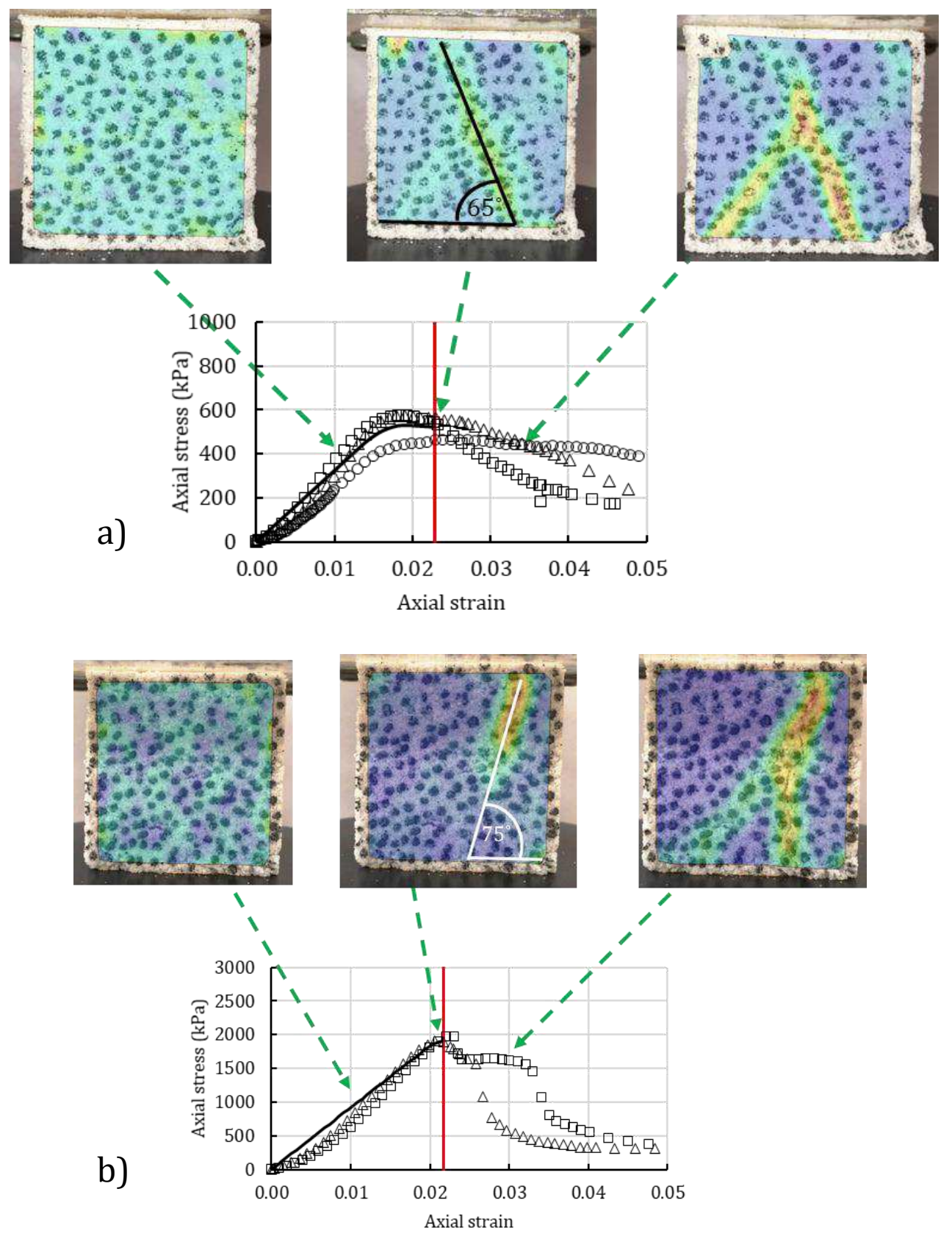
Material

$\mathrm{E}(\mathrm{MPa})$

$\beta\left({ }^{\circ}\right) \quad d(\mathrm{MPa}) \psi\left(\left(^{\circ}\right)\right.$

v

Plain soil

88

34

0.7

0

0.3

GG (1\%)

234

63

0.72

0

0.3

GG (2\%)

217

64

0.48

0

0.3

GG (4\%)

184

65

0.79

0

0.3

BG (1\%)

114

42

0.1

0

0.3

BG (2\%)

130

46

0.85

0

0.3

BG (4\%)

162

55

0.87

0

0.3

XG (1\%)

249

54

1

0

0.3

XG (2\%)

243

51

1

0

0.3

$X G(4 \%)$

233

46

1.9

0

0.3 